\title{
Treatment of toxic metal aqueous solutions: encapsulation in a phosphate- calcium aluminate matrix
}

\author{
J.M. Fernández ${ }^{a}$, I. Navarro-Blasco ${ }^{a}$, A. Duran ${ }^{a}$, R. Sirera ${ }^{a}$, J.I. Alvarez ${ }^{a^{*}}$
}

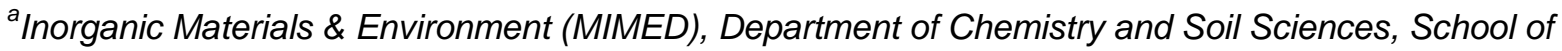
Sciences, University of Navarra. Irunlarrea, 1. 31008 Pamplona, Spain

http://dx.doi.org/10.1016/j.jenvman.2014.01.044

\begin{abstract}
Polyphosphate-modified calcium aluminate cement matrices were prepared by using aqueous solutions polluted with toxic metals as mixing water to obtain wastecontaining solid blocks with improved management and disposal. Synthetically contaminated waters containing either $\mathrm{Pb}$ or $\mathrm{Cu}$ or $\mathrm{Zn}$ were incorporated into phosphoaluminate cement mortars and the effects of the metal's presence on setting time and mechanical performance were assessed. Sorption and leaching tests were also executed and both retention and release patterns were investigated. For all three metals, high uptake capacities as well as percentages of retention larger than $99.9 \%$ were measured. Both $\mathrm{Pb}$ and $\mathrm{Cu}$ were seen to be largely compatible with this cementitious matrix, rendering the obtained blocks suitable for landfilling or for building purposes. However, $\mathrm{Zn}$ spoilt the compressive strength values because of its reaction with hydrogen phosphate anions, hindering the development of the binding matrix.
\end{abstract}

${ }^{*}$ Corresponding author:

Dr. José I. Alvarez

University of Navarra

Irunlarrea, 1. 31008 Pamplona, Spain

Phone: +34948425600

Fax: +34948425740

E-mail: jalvarez@unav.es, mimed@unav.es 


\section{INTRODUCTION}

The release of toxic metals into the environment is a matter of growing concern for environmental stakeholders (Shaheen et al., 2013; Gollman et al., 2010). Different approaches have been used to address problems arising from spills into natural waters, industrial polluted sludge, slurries and soils, contaminated wastewaters and so on (Devasena and Nambi, 2013; Diamantis et al., 2013).

One of the most widespread alternatives for handling toxic metal solutions is encapsulating them in manageable solid blocks that allow the proper solidification/stabilization (S/S) of hazardous components and their subsequent safe disposal in landfill sites (Ucaroglu and Talinli, 2012). Among the binding materials used to form these solid blocks, cements have been proved to be suitable and costsaving agents (Ojovan et al, 2011; Liu et al., 2013; Pandey et al., 2012).

Ordinary Portland cement (OPC) has been widely studied as a good heavy metal retainer, but the use of other alternative binders is receiving growing attention. For instance, the use of calcium aluminate cement (CAC) to safely encapsulate hazardous materials has been recognized to be highly effective (Navarro-Blasco et al., 2013). The relatively low pH of this kind of cement matrix (10.5-11.5), in comparison with the OPC system, has been highlighted as a favourable property for high and intermediate level waste (HLW and ILW) repositories because of its acidic chemical attack resistance (García-Calvo et al., 2013; Swift et al., 2013a). Furthermore, the high early strength, abrasion endurance, and the possibility of low ambient temperature application, have been reported as other advantages related to using CAC (Ukrainczyk et al., 2012).

A variant of a CAC matrix is phosphate-bonded calcium aluminate cement, which can be obtained by acid-base reaction between acidic phosphate solutions (for example, polyphosphate) and calcium aluminate cement as the base reactant (Sugama and Carciello, 1995). The use of these phosphate modified calcium aluminate cements as potential cementing system for encapsulation of radioactive wastes (Swift et al., 2013b) and to prevent the aluminium containing nuclear wastes from corrosion (Kinoshita et al., 2013) has been investigated.

It has been reported that amorphous reaction products are responsible for these materials' performance. The nature of these products is still a matter of controversy, as some authors indicate that these products are composed of calcium aluminate phosphate hydrates, C-A-P-H, (Ma and Brown, 1994), whilst others state that amorphous calcium phosphate (ACP) and alumina gel $\left(\mathrm{Al}_{2} \mathrm{O}_{3} \cdot \mathrm{xH}_{2} \mathrm{O}, \mathrm{AH}_{3}\right)$ are the main chemical components (Sugama and Carciello, 1995; Swift et al., 2013b). These matrices of calcium phosphate cements are characterized by their rapid setting, increased mechanical strength and low internal $\mathrm{pH}$. Furthermore, the acidbase reaction between polyphosphate and CAC results in a porosity reduction (Sugama, 1996). Taking into consideration all these findings, the rationale for the current work is the advantageous use of polyphosphate-CAC matrices in the S/S of toxic metal solutions, given that: 
i) The $\mathrm{pH}$ decrease with respect to the CAC matrices could make it easier to form precipitates of metal hydroxides of cations with strong amphoteric character (such as $\mathrm{Zn}(\mathrm{II})$ or $\mathrm{Pb}(\mathrm{II})$, for example) (Malviya and Chaudhary, 2006). In high pH media, hydroxides of amphoteric cations could be redissolved by formation of oxoanions, thus increasing the mobility and subsequent leaching of the toxic metal (Ukrainczyk et al., 2012).

ii) Generally, the presence of heavy metals interferes with the hydration process of the cementitious compounds (both in OPC and in CAC mortars). Many of the metals act as strong setting retarders, with deleterious effects on the mechanical strengths (Fernández Olmo et al., 2001; Navarro-Blasco et al., 2013). The use of a different matrix, with rapid setting time and high mechanical strength, could be useful to mitigate or even cancel the consequences of the metal presence.

iii) The reduction in porosity would benefit the immobilization of the toxic metals, stopping water from reaching the inner part of the mortar.

All these issues could make the management and disposal of toxic metal wastes in landfills safer and easier. Moreover, the preparation of controlled-low-strength materials could be another possibility for the end-use of these materials (Zhen et al., 2013; Naganathan et al., 2013; Yan and Sagoe-Crentsil, 2012; Lertwattanaruk et al., 2012).

Therefore, the aim of this study is to explore the use of phosphate-modified iron-rich calcium aluminate cement as a matrix to encapsulate polluted waters with toxic metals $(\mathrm{Pb}, \mathrm{Zn}$ and $\mathrm{Cu})$. These metals have been found to be commonly present in industrial effluents (Ahmaruzzaman, 2011) and were selected as the target metals in S/S processes in other cementitious matrices (Navarro-Blasco et al., 2013). Several polyphosphate-CAC mortars were prepared and modified upon the addition of artificially contaminated aqueous solutions each containing one of the target metals. The influence on the setting time and on the compressive strengths was studied. Mineralogical study by X-ray diffraction, pore size distribution and microstructural examination were also conducted to assess the effect of the presence of the toxic metal. Batch sorption studies as well as monolith leaching tests were carried out to research the effectiveness of this polyphosphate-CAC matrix for metal immobilization and to obtain an insight into the release patterns of these metals. 


\section{MATERIAL AND METHODS}

\subsection{Material}

To prepare the different batches of specimens, the binding matrix was formed by acid-base reaction between an iron-rich calcium aluminate cement (CAC) as the base reactant (Electroland $^{\circledR}$, supplied by Ciments Molins S.A.) and sodium hexametaphosphate (SHMP) (from Merck, $\left.\left(\mathrm{NaPO}_{3}\right)_{6}\right)$, a polyphosphate that acted as the acidic reactant. The X-ray powder diffraction (XRD) data showed that the crystalline components of CAC consisted of a main mineralogical phase, CA (ICDD 01-070-0134), together with $\mathrm{C}_{12} \mathrm{~A}_{7}$, mayenite, (ICDD 09-0413), $\mathrm{C}_{5} \mathrm{~A}_{3}$ (ICDD 01 1057), $C_{3} A$ (ICDD 01-1060) and $C_{4} A F$ (ICDD 30-0226). The chemical constituents are as follows: 41 wt. $\% \mathrm{Al}_{2} \mathrm{O}_{3}, 38 \% \mathrm{CaO}, 17 \% \mathrm{Fe}_{2} \mathrm{O}_{3}, 3.0 \% \mathrm{SiO}_{2}, 0.1 \% \mathrm{SO}_{3}$, and $0.1 \% \mathrm{Na}_{2} \mathrm{O} / \mathrm{K}_{2} \mathrm{O}$.

A standard siliceous sand (99 wt.\% of $\mathrm{SiO}_{2}$ with particle diameter ranging from 0.05 to $2 \mathrm{~mm}$ ), provided by the Eduardo Torroja Institute, was also incorporated as an aggregate. Synthetic contaminated waters were prepared by the individual addition of soluble nitrates of lead, copper and zinc, respectively (Merck) in a metal concentration of $27 \mathrm{~g} \mathrm{~L}^{-1}$. In good agreement with contaminated water streams, the prepared polluted waters had acidic $\mathrm{pH}$ values of $5.23,4.33,4.82$, respectively. This amount of metal turned out to be much larger than reported values found in industrially polluted wastewaters (Shaheen et al., 2013; Noruzman et al., 2012) and exceeded the tolerable limits for industrial effluent discharge. Polluted aqueous solutions were added as mixing water in order to reach a ratio of $1 \mathrm{w} / \mathrm{w} \%$, toxic metal/binder.

\subsection{Mortar preparation}

Calcium aluminate cement, SHMP and siliceous sand were blended for $5 \mathrm{~min}$ in a mixer. The binder/aggregate and cement/SHMP ratios were $1 / 1.5$ and $1 / 0.2$ by weight, respectively. The mixing water used (ratio of $0.37 / 1$ water/cement) was the artificially metal-contaminated solution. All the components were mixed for $90 \mathrm{~s}$ at low speed.

Fresh mixtures were poured in cylindrical $(5 \mathrm{~cm}$ height and $3.5 \mathrm{~cm}$ diameter) PVC moulds and cured for 28 days using two different curing regimes:

i) Curing condition $1: 20^{\circ} \mathrm{C}$ and $95 \% \mathrm{RH}$ through the whole curing period;

ii) curing condition $2: 60{ }^{\circ} \mathrm{C}$ and $100 \% \mathrm{RH}$ for $24 \mathrm{~h}$ and then completed at 20 ${ }^{\circ} \mathrm{C}$ and $95 \% \mathrm{RH}$ over the rest of the curing period.

While the first curing regime is common with OPC-based materials, the second one, a hydrothermal curing regime, was selected because in calcium aluminate cements it has been found to enhance the formation of stable calcium aluminate hydrates, the so-called conversion reaction (Sakai et al., 2010; Sugama and Carciello, 1992). 
Given that in the present experiment calcium aluminate cement was one of the main components of the binder, the comparative study on the two curing conditions was thought to be of interest.

Although the main reactions responsible for the setting process in these SHMPCAC mortars are different from those that take place in a plain CAC mortar, it is reasonable to expect that a certain number of calcium aluminate compounds that remained unreacted after the acid-base process can form calcium aluminate hydrates. It must be considered that, in the present study, the CAC/SHMP ratio was just $1 / 0.2 \mathrm{w} / \mathrm{w}$, so that an excess of CAC was evident and the presence of unreacted calcium aluminate compounds is plausible. If the conversion reaction had taken place, denser hydrates would be formed and the overall porosity of the hardened specimens would be increased, thus reducing the strength.

A total of four different batches were prepared: a metal-free phosphate-calcium aluminate mortar (as a control group) and three different metal-doped batches of samples by the addition of metal-polluted mixing water. Thus, three specimens of each one of the different mortar compositions for each period of curing $(1,3,7,14$ and 28 days) were prepared to ensure the statistical significance of data. Graphical representations include error bars by means of the standard deviation with respect to the mean of the three experimental values.

\subsection{Experimental methodology}

Characterization of the setting time was carried out by means of a specific device provided with a bradawl, which pushed the fresh sample until the strength exerted to introduce it into the sample was larger than $15 \mathrm{~N}$, according to the norm (EN1015-9, 2000).

After each one of the curing periods, the compressive strength of the cylindrical specimens was assessed on a Proeti ETI 26.0052 at a loading rate of $50 \mathrm{~N} \mathrm{~s}^{-1}$. In addition, pore size distributions (PSD), microstructural examination by SEM and mineralogical study, by XRD, were also executed at each curing stage. PSD were obtained by mercury intrusion porosimetry (MIP) using a Micromeritics AutoPorelV9500 with a pressure ranging between 0.0015 and $207 \mathrm{MPa}$. Scanning Electron Microscopy (SEM) in a Zeiss microscope coupled to an EDS detector was used for textural observation of the mortar samples and elemental mapping. X-ray diffraction (XRD) was carried out by means of a Bruker D8Advance diffractometer (Karlsruhe, Germany), with a $\mathrm{Cu} \mathrm{K}_{\alpha 1}$ radiation and a step size of $0.02^{\circ}$ and a time per step of $1 \mathrm{~s}$, from $2^{\circ}$ to $50^{\circ}(2 \theta)$.

Aqueous slurries $\left(50 \mathrm{mg} \mathrm{L}^{-1}\right)$ of phosphate-CAC cement $(20 \%$ wt. phosphatecement ratio) were prepared to carry out the mono-metal sorption assays. To assess the effect of the counterion, both nitrates and chlorides of each one of the 
three toxic metals were tested. Either nitrates or chlorides of selected metals were added ranging from 0 to $20 \% \mathrm{wt}$. regarding to the cement sorbet system. The mixtures were allowed to reach equilibrium under stirring for $60 \mathrm{~min}$. The solid compounds were extracted by centrifugal separation and the supernatant was filtered through a $0.45 \mu \mathrm{m}$ syringe-filter. Residual solid phase was assessed by $X R D$, while the level of metal concentration remaining in solution was determined by atomic absorption spectrometry (AAS, PerkinElmer AAnalyst-800). Steady-state data were fitted to the Langmuir and Freundlich models.

A semi-dynamic Tank Test (EA NEN 7375, 2004) that had been proved useful to elucidate leaching mechanisms in this type of cement-based matrices (Yang et al., 2011) was used according to the procedure described elsewhere (Lasheras-Zubiate et al., 2011). Monolithic test pieces, molded and cured as aforementioned, were assayed in duplicate. The specimens were placed in a cubic methacrylate container (110 $\mathrm{mm}$ side length), and then filled with $1 \mathrm{~L}$ of ultrapure demineralized water. Water aliquots, previously filtered through a $0.45 \mu \mathrm{m}$-pore size nylon membrane, were collected at eight different times $(0.25,1,2.25,4,9,16,36$ and 64 days), where conductivity and $\mathrm{pH}$ were measured with a 4-Star benchtop $\mathrm{pH} /$ conductivimeter (Thermo). Afterwards, $10 \mathrm{~mL}$ of eluates, preserved by the addition of $10 \mu \mathrm{L}$ of sub-boiling $\mathrm{HNO}_{3}$, were stored at $-20^{\circ} \mathrm{C}$ until AAS analysis.

The measured cumulative leaching and derived cumulative leaching for each component was calculated as described in Supplementary materials (section 1 of the Supplementary materials, Calculations for the leaching parameters determination). The interpretation of the slopes followed the criteria of the norm and agreed with previous works (Moon and Dermatas, 2006; Ginés et al., 2009; Lampris et al., 2011; Lasheras-Zubiate et al., 2012) Similarly the calculation of the negative logarithm of the effective diffusivity $\left(\mathrm{pD}_{e}\right)$ (leachability index) was reported in Supplementary materials (section 1).

As reported in the criteria set out in the norm and in previous work such as that of Malviya and Chaudhary (2006), the higher the $\mathrm{pD}_{\mathrm{e}}$, the lower was the leaching rate. Values below 11.0 indicated high mobility, results between 11.0 and 12.5 indicated average mobility and values above 12.5 indicated low mobility of the component. When the diffusion coefficient was expressed in $\mathrm{cm}^{2} \mathrm{~s}^{-1}$, instead of $\mathrm{m}^{2} \mathrm{~s}^{-1}$ as in the present work, some other regulations referred it as $\mathrm{LI}$ (leachability index) requiring values higher than 6 (acceptance of nuclear wastes in controlled sites) or higher than 9 for controlled use of the solidified wastes (Torras et al., 2011).

To assess the metal-binder interaction, distributions of the species concentration as a function of $\mathrm{pH}$ for the three toxic metals were built by using the approach provided by the Hydra/Medusa Chemical Equilibrium Database and Plotting Software (Puigdomenech, 2004). 


\section{RESULTS AND DISCUSSION}

\subsection{Setting time, mechanical performance and microstructural analysis}

\subsubsection{Curing condition 1}

SHMP-treated CAC mortars showed a short setting time ( $5 \mathrm{~min}$ ) and, after 28 curing days the compressive strength achieved a value of $33 \mathrm{MPa}$ (Fig. 1a). The short setting time was in line with data reported by Swift et al. (2013b). However, on the mechanical strength, data from literature show higher values: in general, the polyphosphate-modified mortars attained compressive strengths in the range from 90 to $100 \mathrm{MPa}$ after 28 curing days (Swift et al. 2013b, Li et al., 2007). Differences could arise from the different chemical composition of the raw CAC, since in the present work an iron-rich CAC cement (17 wt.\% of $\mathrm{Fe}_{2} \mathrm{O}_{3}$, similar to Ciment Fondu ${ }^{\circledR}$ ) was used, instead of an iron-lean CAC employed in the papers quoted (< $2 \mathrm{wt} . \% \mathrm{Fe}_{2} \mathrm{O}_{3}$ ). As a consequence of this chemical composition, in our experiment, the extent of the acid-base reaction between the acidic phosphate compound and the base reactant (calcium components) to form the main binding phase was limited, as will be discussed below.

In comparison with unmodified CAC specimens, the setting time was clearly reduced upon the addition of SHMP (from $178 \mathrm{~min}$ to $5 \mathrm{~min}$ ) and compressive strength underwent a slight reduction (strength drop of 13.4\%). In spite of this fact, SHMP-CAC mortars showed a reasonable mechanical resistance. At the same time, owing to the short setting time, these SHMP-CAC matrices could be useful when a rapid encapsulation of toxic metal solutions is needed.

When the different metal-polluted waters assayed here were added to the SHMPcalcium aluminate cement, the slurries obtained showed different performance with respect to fresh-state properties and mechanical behaviour, always depending on the specific contaminating toxic metal.

A delay in the setting time was observed: in the case of $\mathrm{Pb}$ and $\mathrm{Cu}$, the setting time was still within common limits, ranging from ca. 50 min to 3.5 hours, respectively, so that the solidification/stabilization of $\mathrm{Pb}$ - and $\mathrm{Cu}$-containing wastewaters in $\mathrm{a}$ phosphate-modified CAC could easily be achieved.

Compressive strength after 28 curing days, curing condition 1, was as large as 39.8 MPa for Pb-doped sample (Fig. 1a), and thus even higher than that of the metalfree control group. For the Cu-doped specimen, strengths over the different curing periods were around $20 \mathrm{MPa}$ (Fig. 1a). These findings involve an improvement with respect to the S/S processes with wastewaters containing both metals in unmodified CAC matrices, in which, according to reported values, after 28 curing days - curing condition 1 -, Pb-CAC and Cu-CAC samples yielded, respectively, just 9.7 MPa and 0.8 MPa (Navarro-Blasco et al., 2013). While the presence of either $\mathrm{Pb}$ or $\mathrm{Cu}$ was 
largely detrimental for the compressive strength of the plain CAC mortars, the S/S processes of contaminated waters with these metals in a SHMP-modified CAC matrix resulted in more resistant solidified blocks. The low mechanical strengths reported in metal-doped plain CAC systems were related to the hindrance of the hydration of the calcium aluminate compounds owing to the metals' presence. However, in the presence of SHMP, the hydration mechanism - and thus the hardening - was modified, resulting in the appearance of ACP as the main binding phase (Swift et al., 2013b). Neither Pb nor Cu seemed to interact greatly with the formation of this binder, so that the compressive strengths attained high values.

The study of phase assemblage by XRD under curing condition 1 showed that the addition of the SHMP hindered the hydration of the CAC phases after early curing periods and yielded a poor crystalline diffraction pattern (Fig. 2a). As a matter of fact, anhydrous calcium aluminate phases such as $C A$, gehlenite, $C_{2} A S$ and $C_{12} A_{7}$ could be found, tending to be reduced from day 14 onwards. These findings were in line with the inhibitory effect for the polyphosphate with respect to the hydration of CAC compounds earlier reported and with the appearance of ACP-based binding matrix (Swift et al., 2013b; Ma and Brown, 1994; Walter and Odler, 1996). After 28 curing days, metal-free SHMP-CAC mortar showed the formation of an aluminium phosphate and low amounts of a metastable calcium aluminate hydrate $\left(\mathrm{CAH}_{10}\right)$. However, the interpretation of these results has to be cautiously considered owing to the low crystalline character of the XRD patterns.

The addition of polluted waters with either $\mathrm{Pb}$ or $\mathrm{Cu}$ did not involve significant changes in the XRD analyses, apart from a reduction in the formation of $\mathrm{CAH}_{10}$ and aluminium phosphate. By way of example, Fig. $2 b$ shows the XRD patterns of all samples after 28 days under curing condition 1.

Pore size distributions accounted for the compressive strength results (Fig. 3a). The CAC matrix modified with polyphosphate showed an almost unimodal PSD with a mean pore size of $0.03 \mu \mathrm{m}$. The addition of either $\mathrm{Pb}$ or $\mathrm{Cu}$ also resulted in unimodal PSD distributions with relatively low porosity. This fact matched perfectly the high mechanical strength values. Nevertheless, the presence of copper caused a shift of the pores towards larger diameters, in good agreement with the slight decrease in strength (Fig. 1a).

The microstructural examination of the metal-free calcium phosphate aluminate cement showed an amorphous, gel-like matrix in which a few almost prismatic crystals could be found (Fig. 4a). These prismatic crystals can be ascribed to $\mathrm{CAH}_{10}$ phases, as identified by XRD. Some microcracks could also be observed (Fig. 4b). These cracks have been reported to be a consequence of the exothermic acid-base reactions between polyphosphates and calcium aluminate compounds (Swift et al. 2013b). 
Elemental mapping carried out by means of EDS analysis (Fig. 5) showed that phosphorus, aluminium, iron and calcium appeared in the same areas whilst siliconbased components were found to be part of other different areas. Since an iron-rich CAC was used, in this work Fe was also found to be associated with phosphorus. The disentanglement of this fact will be tackled below.

Upon the use of wastewaters containing $\mathrm{Pb}$, the textural examination of the sample revealed a more homogeneous, glassy matrix (Fig. 4c and 4d). There is no evidence for the presence of large amounts of isolated prismatic crystals, in good accordance with the low amount of $\mathrm{CAH}_{10}$ determined by XRD analysis. The observed high degree of compactness of the binding matrix agrees with the pore size distribution and would explain the large mechanical resistance of this sample.

In the presence of $\mathrm{Cu}$, the binding matrix in Fig. $4 \mathrm{e}$ showed more microcracks and a lower degree of homogeneity that would justify the drop in strength and the higher porosity of this sample compared to Pb-doped sample. The heterogeneity of this specimen was proved by the micrograph in Fig. $4 \mathrm{f}$, in which several different areas appeared interlocked together with some single prismatic crystals as well as clusters of them scattered on the surface.

As for Zn-doped samples, our results departed from those just mentioned for either $\mathrm{Pb}$ or $\mathrm{Cu}$. Zinc appeared to dramatically interfere with the binding matrix of the phosphate-CAC system. As a result, the setting time underwent a strong delay of almost 2 days and, at the same time, the mechanical strengths greatly decreased giving almost negligible values (as low as $0.7 \mathrm{MPa}$ after 7 days of curing) (Fig. 1a), which did not fulfil the above discussed minimum strength values for disposal or secondary uses. After 28 curing days, compressive strength rose, reaching a maximum value of $12.4 \mathrm{MPa}$.

The literature has shown that $\mathrm{Zn}$ acts as an inhibitor of the hydration and setting processes of different cementitious matrices, including ordinary Portland cement, leading to strong delays in the hardening and low mechanical strengths (Fernández Olmo et al., 2001; Gineys et al., 2010; Berger et al., 2011). In the present case, the presence of $\mathrm{Zn}$ also had a detrimental effect on the setting process so that the amount of hydrated compounds was reduced, as observed by XRD for $\mathrm{Zn}$ containing SHMP-CAC mortars (Fig. 2b). An insight into the interaction mechanism will be presented in section 3.4 , below.

The PSD profile of the Zn-doped phosphate-CAC mortar observed (Fig. 3a) again showed a departure from those of the other two studied metals which can be summarized as: (i) a displacement of the mean pore size towards larger pore diameters (ca. $2 \mu \mathrm{m})$; and (ii) an outstanding increase of the overall porosity, as proved by the increase in the total volume of intruded mercury. These two effects agreed well with the lower compressive strengths of these $\mathrm{Zn}$-doped mortars. An explanation to this fact is described in section 3.4 below. 
The microstructural examination by SEM also confirmed the previous results. SEM micrographs show a heterogeneous matrix, with several deposits of anhydrous calcium aluminate compounds (Fig .4g), with large porosity and poorly interlocked binder (Fig. 4h and 4i) and with a large number of microcracks (Fig. 4j).

To summarize, with respect to fresh-state as well as mechanical properties in the hardened state, the phosphate-CAC matrix showed good performance for solidification/stabilization of either $\mathrm{Pb}$ or $\mathrm{Cu}$ from wastewaters used as mixing waters for the obtaining of the solid blocks. These matrices satisfied the compressive strength requirements of, among others, the minimum value of $1 \mathrm{MPa}$ of a norm for disposal of solid wastes to landfills (Environment Agency, 2010) and the threshold value of $3.45 \mathrm{MPa}$ of a norm for secondary waste forms (U.S. NRC, 1991). With respect to the masonry mortars norm (EN 998-2, 2010) all the mortars doped with either $\mathrm{Pb}$ or $\mathrm{Cu}$ could be classified as M15 mortars and several of them as M20 or superior, allowing, as an alternative, the use of these binding materials for building purposes (Gritsada and Makul, 2013).

\subsubsection{Curing condition 2}

The compressive strengths over the time of the metal-free sample evidenced the occurrence of the conversion reaction: the mechanical resistance was lower than that of the same samples after curing condition 1 and, from day 3 onwards, a strength regression was clear (Fig. 1b). Similar strength regressions have been ascribed in the literature to the conversion phenomenon (Swift et al., 2013b). In order to confirm this fact, XRD analysis of this sample showed the presence of stable hydrates (namely $\mathrm{AH}_{3}$ and $\mathrm{C}_{3} \mathrm{AH}_{6}$ ) (Fig. $2 \mathrm{c}$ ). Similar results were found for the $\mathrm{Pb}$-doped samples: a slight reduction in the compressive strength together with the identification by XRD of a certain amount of stable calcium aluminate hydrates.

The larger porosity as well as the increasing amount of microcracks (probably induced by the hydrothermal curing regime) could be seen, respectively, in the SEM micrographs of the Pb-doped samples (Fig. 6a and 6b). Furthermore, the PSD of a $\mathrm{Pb}$-doped sample after this second curing condition showed a clear displacement of the mean pore size towards larger diameters (ca. $0.6 \mu \mathrm{m}$ ) (Fig. 3b), in comparison with PSD of the samples cured under condition 1 (mean pore size of ca. $0.02 \mu \mathrm{m}$ ) (Fig. 3a).

In the case of Cu-doped samples, this curing condition clearly favoured the compressive strengths of the samples. By way of explanation, an according to the SEM examination (Fig. $6 \mathrm{c}$ and $6 \mathrm{~d}$ ), the hydrothermal curing regime enhanced the formation of an interlocking structure of plate-like crystals, which could be related to the formation of hydroxyapatite, identified by XRD (Fig. 2c). This micromorphology tends to fill the interspaces between non-crystalline products (smooth surface texture area in the SEM images). As a result, these compounds yielded a densified 
structure, with a clear porosity reduction, and, at the same time, the cross-linking action provided an interlinked matrix. These two facts enhanced the mechanical strength of the matrix. These findings were in line with those reported by Sugama and Carciello (1991) for hydrothermally cured phosphate-bonded calcium aluminate cements.

With respect to Zn-doped samples, curing regime 2 did not substantially modify the mechanical performance. As a general trend, all the samples assayed showed poor compressive strengths (Fig. 1b). The analysis of the hardened specimens by XRD allowed us to determine a large amount of anhydrous calcium aluminate components ( $C A, C_{12} A_{7}$ y $C_{2} A S$ ), so that it can be inferred that, despite the hydrothermal curing regime, the presence of $\mathrm{Zn}$ in the contaminated mixing water strongly hampered the setting process and the hydration of the anhydrous calcium aluminates. Porosity and pore size distribution were similar to those measured for Zn samples after curing condition 1: high overall porosity and large mean pore size (Fig. 3c). These facts were in accordance with the low mechanical strength. The microstructural examination showed quite a heterogeneous binder, with some areas resembling a spongy texture, with several microcracks (Fig. 6e and 6f). In some areas, a growth of a few needle-shaped crystals was observed (Fig. $6 \mathrm{~g}$ and $6 \mathrm{~h}$ ) and could be related to the formation of hydroxyapatite (Domínguez et al., 2008); as seen by XRD in Zn-doped samples (Fig. 2c). However, its acicular micromorphology - that was diverse from that above discussed for the Cu-doped specimens - did not allow the formation of either a dense structure or an interlocked binding phase. Therefore, large pore sizes and low mechanical resistances were observed for these samples.

\subsection{Metal sorption}

The ability of the phosphate-bonded CAC system to perform metal sorption from contaminated water was studied. In this study, the different wastewaters included the targeted metals but with two different counterions (chlorides and nitrates, in Fig. S1 and Fig. S2 of the Supplementary materials). The use of metal standard solutions prepared from chloride salts provided better sorption results. From calculated data (Table S1 in Supplementary materials), it is clear that $\mathrm{Cu}$ adjusted preferentially to a Langmuir isotherm in either $\mathrm{Cu}\left(\mathrm{NO}_{3}\right)_{2}\left(\mathrm{R}^{2}=0.998\right)$ or $\mathrm{CuCl}_{2}\left(\mathrm{R}^{2}=\right.$ 0.909) form..

Excellent maximum sorption capacities of up to $90.79 \mathrm{mg} \mathrm{g}^{-1}$ for $\mathrm{Cu}$ were calculated when added as a chloride salt, and over $66 \mathrm{mg} \mathrm{g}^{-1}$ when present in the nitrate form (Table S1, Supplementary materials). Also for $\mathrm{Pb}$ maximum adsorption values were relevant, with a highest capacity of ca. $35 \mathrm{mg} \mathrm{g}^{-1}$ for the chloride salt. In the case of $\mathrm{Zn}$, despite the detrimental effects caused when $\mathrm{Zn}$ was added to a phosphate-CAC matrix, a maximum sorption capacity value close to $56 \mathrm{mg} \mathrm{g}^{-1}$ was calculated when it was introduced as a chloride. 
It must be noticed that, in comparison with sorption values reported in the literature for some similar sorbent materials, the maximum uptake capacities of this SHMPcalcium aluminate cement matrix for the three assayed metals from the wastewaters were high, especially for $\mathrm{Cu}$ as well as for $\mathrm{Zn}$ sorption (Table S2, Supplementary materials).

After the sorption tests, samples were centrifugated and solid fractions were afterwards subjected to a freezing-drying procedure and studied by XRD (Fig. S3 in Supplementary materials). Results showed patterns with an amorphous part (suggesting the presence of amorphous/poor crystalline products) and some diffraction peaks. Among the latter, anhydrous calcium aluminate compounds were predominant, especially $\mathrm{CA}$ and $\mathrm{C}_{12} \mathrm{~A}_{7}$ or, to a lesser extent, gehlenite. There were some weak diffraction peaks evidencing the formation of hydrated compounds, but just in $\mathrm{Pb}$ - or $\mathrm{Cu}$-doped samples, for example $\mathrm{CAH}_{10}, \mathrm{AH}_{3}$ (gibbsite) or $\mathrm{C}_{3} \mathrm{AH}_{6}$ (hydrogrossular). Zn-doped samples seem not to show hydrated products such as $\mathrm{AH}_{3}$. No well-crystallized phases incorporating the toxic metals added were found.

\subsection{Leaching studies}

The values shown in Table 1 prove the effective retention of the three toxic metals from the polluted aqueous solutions: in all cases toxic metals were retained more than $99.9 \%$. Data belonging to the $64^{\text {th }}$ day showed that ca. $5 \mathrm{mg} \mathrm{m}^{-2}$ of any of the three metals were cumulatively leached when the mortars had been cured under the curing condition 1 . The hydrothermal curing regime favored especially the retention of $\mathrm{Cu}$ : the cumulative leaching went down to just 0.83 in specimens hydrothermally cured (condition 2). This fact could be related to the porosity reduction of $\mathrm{Cu}$-doped specimens discussed above, owing to the formation of hydroxyapatite. It was thus proved that immobilization of $\mathrm{Cu}$ was best of all and had a corresponding excellent resistance performance when hydrothermally cured.

In comparison with previous values reported concerning the retention of toxic metals in cementitious matrices, the retention percentages of the three toxic metals were excellent (Habib et al., 2012; Giergiczny and Król, 2008; Zhang et al., 2009). With respect to the disposal of the tested monolithic blocks in landfills, cumulative leaching values were well below the regulated emission limits as shown in the Table 3. Taking into account the high concentration of the toxic metals in the contaminated waters tested in this study, the efficiency of this SHMP-CAC matrix for the treatment of wastewaters was evident.

Table 2 collects the leaching data analysis from the log-log plots of derived cumulative leaching (Fig. S4 in Supplementary materials). Both $\mathrm{Cu}$ and $\mathrm{Zn}$ were released following a global wash-off pattern from the monolithic specimens under any of the curing conditions assayed, the stages involved being delayed diffusion 
and depletion. This global wash-off mechanism is a fast way of releasing the most soluble metal-bearing compounds on the surface of the monolithic sample.

On the other hand, $\mathrm{Pb}$ in mortars subjected to curing condition 1 showed an initial delayed diffusion, followed by diffusion and dissolution stages ending up in a global diffusion leaching pathway. Under these circumstances, the EA NEN 7375 norm (2004) allows the effective diffusion coefficient to be safely estimated. In this case, for $\mathrm{Pb}$-bearing samples, the $\mathrm{pD}_{\mathrm{e}}$ achieved was as high as 19.84 , which implied a very low mobility. Taking into account the different units and leaching periods used, our diffusion coefficient was comparable with reported values for S/S processes of $\mathrm{Pb}$ in other matrices (Wagh et al., 1997; Moon and Dermatas, 2006).

Under curing condition 2, the mechanism of the $\mathrm{Pb}$ release became fully dissolution-controlled.

All in all, retentions were exceedingly good for the three toxic metals from the polluted aqueous solutions, irrespective of the leaching pathways followed by any of the metals. The relevance of the leaching patterns should be considered cautiously owing to the small amount of the released metal over the long assay time.

\subsection{Metal-binder interaction}

To gain knowledge about the interaction mechanism and keeping in mind the outstanding differences between, on the one hand, the performance of $\mathrm{Zn}$-polluted waters and, on the other hand, the $\mathrm{Pb}$ - and Cu-bearing wastewaters, the metal speciation according to the chemical equilibrium model and solubility equilibria diagrams for the three metals vs. $\mathrm{pH}$ values was obtained and carefully examined (Fig. S5, in Supplementary materials). According to the reported data (Li et al., 2007; Sugama et al., 1999) and to our experimental measures, the $\mathrm{pH}$ of a phosphoaluminate cement matrix usually ranges from 6 to 10.5 (i.e. from slightly acidic to mild alkaline media, depending on the extent of the acid-base reaction). Under these $\mathrm{pH}$ conditions, these diagrams showed that $\mathrm{Zn}$ would prevail as cationic aquosols, $\mathrm{Zn}^{2+}$ or $\mathrm{Zn}(\mathrm{OH})^{+}$, while either $\mathrm{Pb}$ or $\mathrm{Cu}$ would be mainly precipitated as insoluble hydroxydes and oxides $\left(\mathrm{Pb}(\mathrm{OH})_{2}\right.$ and $\mathrm{CuO}$, respectively) (Liu and Liu, 2003; Protopopoff and Marcus, 2005). The formation of these insoluble compounds in the case of $\mathrm{Pb}$ and $\mathrm{Cu}$ also agrees with data reported in magnesium phosphate cements by Buj and co-workers (Buj et al., 2010).

An approach to the processes involved in the formation of the binding phase seems neccesary. To this end, we have taken into account the formation of similar systems, such as chemically bonded phosphate ceramics, which were split into several steps by Wagh and Jeong (Wagh and Jeong, 2003), including: 
(i) dissolution of oxides when stirred into an acid solution, releasing metal cations or, depending on circumstances, oxoanions.

(ii) formation of aquosols by reaction of positively charged cations with water.

These first two steps were recognized to be the controlling processes.

(iii) Acid-base reaction and condensation. The reaction of metaphosphate anions yielded hydrogen phosphate anions $\left(\mathrm{HPO}_{4}{ }^{-}\right)$(Swift et al., 2013b), which would react with the aquosols to form hydrophosphate salts. Hydrophosphate salts would give rise to a network, eventually resulting in a gel, and

(iv) in the end, the growing amount of hydrophosphates would thicken and saturate the gel that would end up in the formation of a crystallized product.

In the case of the phosphate-modified calcium aluminate cement, the rate of the exothermic heat production - by the acid-base reaction - was too fast to allow the phosphate gel to crystallize slowly into a well-ordered ceramic, so that this is the main reason explaining the amorphous pattern of the binding matrix, contrasting with the process for obtaining ceramic materials.

Experimental results such as the delayed setting time, low strength, large porosity, large pore sizes and SEM examination showed that the presence of $\mathrm{Zn}$ dramatically prevented the binding matrix from formation, so the question arises about how the presence of $\mathrm{Zn}$ was able to interfere with this process. Our hypothesis is based on the large amount of cationic aquosols of $\mathrm{Zn}$ in comparison with either $\mathrm{Pb}$ or $\mathrm{Cu}$. These $\mathrm{Zn}$ aquosols were able to react with hydrogen phosphate anions yielding insoluble Zn phosphates (Phuong et al., 2013) - with a good entalphy of formation (Wagh and Jeong, 2003) - and thus hindering the calcium from being released from calcium aluminate compounds. The withdrawal of the hydrogen phosphate anions on one side, and the blockage of the calcium release on the other side, obstructed the formation of the binding phase, mainly composed of ACP (Swift et al., 2013b).

Under normal conditions (absence of $\mathrm{Zn}$ ), the formation of calcium phosphate is achieved through a continuous release (and ulterior formation of aquosols) of $\mathrm{Ca}$ (first and second step) from the anhydrous calcium aluminates, resulting in decalcified compounds and thus aluminium-enriched, which in further hydration yield $\mathrm{Al}_{2} \mathrm{O}_{3} \cdot \mathrm{xH}_{2} \mathrm{O}$ gel $\left(\mathrm{AH}_{3}\right)$ (Sugama et al., 1999). However, in $\mathrm{Zn}$-doped samples, this process is greatly disturbed as a consequence of the presence of cationic aquosols of $\mathrm{Zn}$, with great affinitiy for the hydrogen phosphate anions in a competitive mechanism against $\mathrm{Ca}$ soluble forms. In support of this fact, three pieces of experimental evidence can be put forward: 
a) $\mathrm{AH}_{3}$ was not identified by $\mathrm{XRD}$ in $\mathrm{Zn}$-doped specimens, whereas

b) anhydrous calcium aluminate phases (especially $C A$ and $C_{12} A_{7}$ ) remained in large amounts as clearly depicted by XRD analysis in Zn-treated SHMP-CAC samples (see Figs. $2 b$ and $2 c$ ), and

c) the EDS elemental mapping of $\mathrm{Zn}$-doped samples showed that $\mathrm{Zn}$ was preferentially attached to $\mathrm{P}$ (Fig. 7).

Despite the poor formation of the main binding phase in $\mathrm{Zn}$-doped samples, the sorption and leaching tests proved that $\mathrm{Zn}$ was strongly sorbed and retained in these polyphosphate-modified CAC. This fact can be readily understood in view of the major insolubility of the $\mathrm{Zn}$ hydrophosphates obtained (Wagh et al., 1999). Therefore, a physical encapsulation of these compounds could be reasonably assumed.

Neither $\mathrm{Pb}$ nor $\mathrm{Cu}$ forms soluble cationic aquosols and they are not available to precipitate with phosphates in the slightly acidic - mild alkaline media of these phosphate-modified CAC matrices. Therefore, the formation of the main binding compound, ACP, was not hindered in the $\mathrm{Pb}$ - or Cu-SHMP-CAC samples, thus showing a distinct pattern in comparison with $\mathrm{Zn}$-bearing samples.

As for $\mathrm{Pb}$ and $\mathrm{Cu}$, the physical entrapment of the insoluble hydroxides and oxides, respectively, can also be seen as the main retaining pattern. By way of confirmation, Fig. 8 shows an example of EDS elemental mapping analysis for a $\mathrm{Pb}$-doped sample, in which $\mathrm{Pb}$, as opposed to $\mathrm{Zn}$, appeared to be precipitated all over the surface of the sample and showed no preferential link with $P$.

The proved $\mathrm{Zn}$-interaction with the formation of the ACP supports the fact that, in metal-free samples, the phosphate-modified calcium aluminate cements set and harden by the formation of this ACP and alumina gel, in good agreement with other work (Sugama and Carciello, 1995; Swift et al., 2013b).

Furthermore, in the case of the use of an iron-rich CAC, as in the present study, the presence of large amounts of $\mathrm{Fe}_{2} \mathrm{O}_{3}$ in the raw material could give rise, after the partial dissolution and formation of $\mathrm{Fe}$ aquosols, to a partial withdrawal of hydrogen phosphate anions, thus hindering, to a certain extent, the formation of the ACP, resulting in lower compressive strengths in comparison with polyphosphate-bonded iron-lean calcium aluminate cements, as mentioned in section 3.1.1 above. This interaction between iron-based compounds (oxides) and hydrogen phosphate anions was reported in chemically bonded phosphate ceramics (Wagh and Jeong, 2003). In addition to the compressive strength measurements, other experimental evidence allowed us to confirm this fact, such as the absence of diffraction peaks related to the ferrite phase $\left(\mathrm{C}_{4} \mathrm{AF}\right)$ in the metal-free samples (Torréns-Martín et al., 2013) and the clear Fe-P interaction observed in the elemental mapping of these samples (Fig. 5). 


\section{CONCLUSIONS}

Synthetic wastewaters prepared with a high concentration of either $\mathrm{Pb}, \mathrm{Cu}$ or $\mathrm{Zn}$ were used as mixing water to encapsulate these toxic metals into a phosphatemodified calcium aluminate cement.

The solidified blocks of SHMP-CAC obtained showed good mechanical performance in the presence of either $\mathrm{Pb}$ or $\mathrm{Cu}$, in which the binding matrix exhibited a predominant amorphous microstructure, with a high degree of compactness, yielding low pore sizes.

On the contrary, the presence of $\mathrm{Zn}$ in the polluted mixing water was largely detrimental for the consistency and final compressive strength of the solidified waste. Zn-bearing matrix was seen to be highly porous and heterogeneous. A mechanism of $\mathrm{Zn}$ interaction with the formation of the ACP plus alumina gel has been proposed, based on the enhanced presence of cationic aquosols of this metal that can precipitate with hydrogen phosphate anions.

In batch sorption studies, SHMP-CAC system proved to be an excellent sorbent for the efficient removal of the three toxic metals from artificially polluted waters: values as high as ca. 35, 91 and $56 \mathrm{mg}$ per $\mathrm{g}$ of sorbent material were found for $\mathrm{Pb}, \mathrm{Cu}$ and $\mathrm{Zn}$, respectively.

From the monolith leaching tests, the percentages of metal retained were seen to be over $99.9 \%$ in all instances, in spite of the high metal concentration present in the wastewaters used to manufacture the solid blocks. A physical encapsulation of highly insoluble $\mathrm{Zn}$-hydrophosphates has been described as the plausible retaining mechanism for this toxic metal, while for either $\mathrm{Pb}$ or $\mathrm{Cu}$ the physical entrapment would mainly concern the formation of precipitates including hydroxides/oxides of these metals.

In the case of $\mathrm{Zn}$, although retention values were satisfactory, the mechanical performance of the binding matrix was not suitable to encapsulate this metal. Further studies using an iron-lean calcium aluminate would be of interest.

On the other hand, these phosphate-bonded calcium aluminate cement have been proved to be efficient systems to solidify/stabilize either $\mathrm{Pb}$ or $\mathrm{Cu}$ from wastewaters. Mechanical resistance and leaching behavior make these metal-bearing matrices suitable for either landfill disposal or building materials. 


\section{Acknowledgments}

Ciments Molins for the material supplied. Dr. M. Lasheras-Zubiate (FIDENA) and Dr. M.C. Jiménez de Haro (ICMS) for the SEM analysis. FUNA (Fundación Universitaria de Navarra) for funding under FUNA2013-15108402.

\section{References}

Ahmaruzzaman, M., 2011. Industrial wastes as low-cost potential adsorbents for the treatment of wastewater laden with heavy metals. Adv. Colloid Interfac. 166, 36-59.

Berger,S., Cau Dit Coumes, C., Champenois, J.B., Douillard,T., Le Bescop, P., Aouad, G., Damidot, D., 2011. Stabilization of $\mathrm{ZnCl}_{2}$-containing wastes using calcium sulfoaluminate cement: Leaching behaviour of the solidified waste form, mechanisms of zinc retention. J. Hazard. Mater. 194, 268-276.

Buj, I., Torras, J., Rovira, M., de Pablo, J., 2010. Leaching behaviour of magnesium phosphate cements containing high quantities of heavy metals. J. Hazard. Mater. 175, 789794.

Devasena, M., Nambi, I.M., 2013. In situ stabilization of entrapped elemental mercury, J. Environ. Manage. 130, 185-191.

Diamantis, V., Erguder, T.H., Aivasidis, A., Verstraete, W., Voudrias, E., 2013. Wastewater disposal to landfill-sites: A synergistic solution for centralized management of olive mill wastewater and enhanced production of landfill gas. J. Environ. Manage. 128, 427-434.

Domínguez, M.I., Carpena, J., Borschnek, D., Centeno, M.A., Odriozola, J.A., Rose J., 2008. Apatite and Portland/apatite composite cements obtained using a hydrothermal method for retaining heavy metals. J. Hazard. Mater. 150, 99-108.

EA NEN 7375, 2004. Leaching Characteristics of Moulded or Monolithic Building and Waste Materials. Determination of Leaching of Inorganic Components with the Diffusion Test.

EN-1015-9, 2000. Methods of Test Mortar for Masonry. Part 9: Determination of Workable Life and Correction Time of Fresh Mortar.

EN-998-2, 2010. Specification for mortar for masonry.

Environment Agency, 2010. Waste acceptance at landfills, Bristol.

Fernández Olmo, I., Chacon, E., Irabien, A., 2001. Influence of lead, zinc, iron (III) and chromium (III) oxides on the setting time and strength development of Portland cement, Cement Concrete Res. 31, 1213-1219.

García Calvo, J.L., Alonso, M.C., Hidalgo, A., Fernández Luco, L., Flor-Laguna, V., 2013. Development of low-pH cementitious materials based on CAC for HLW repositories: Long- 
term hydration and resistance against groundwater aggression. Cement Concrete Res. 51, 67-77.

Giergiczny, Z., Król, A., 2008. Immobilization of heavy metals (Pb, Cu, Cr, Zn, Cd, Mn) in the mineral additions containing concrete composites. J. Hazard. Mater. 160, 247-255.

Ginés, O., Chimenos, J.M., Vizcarro, A., Formosa, J., Rosell, J.R., 2009. Combined use of MSWI bottom ash and fly ash as aggregate in concrete formulation: environmental and mechanical considerations. J. Hazard. Mater. 169, 643-650.

Gineys, N., Aouad, G., Damidot, D., 2010. Managing trace elements in Portland cement Part I: Interactions between cement paste and heavy metals added during mixing as soluble salts, Cement Concrete Comp. 32, 563-570.

Gollmann, M.A.C., da Silva, M.M., Masuero, A.B., dos Santos, J.H.Z., 2010. Stabilization and solidification of $\mathrm{Pb}$ in cement matrices. J. Hazard. Mater. 179, 507-514.

Gritsada, S., Makul, N., 2013. Use of limestone powder during incorporation of Pbcontaining cathode ray tube waste in self-compacting concrete. J. Environ. Manage. 128, 931-940.

Habib,M.A., Bahadur,N.M., Mahmood,A.J., Islam,M.A., 2012. Immobilization of heavy metals in cementitious matrices, J. Saudi Chem. Soc. 16, 263-269.

Kinoshita, H., Swift, P., Utton, C., Carro-Mateo, B., Marchand, G., Collier, N., Milestone, N., 2013. Corrosion of aluminium metal in OPC- and CAC-based cement matrices. Cement Concrete Res. 50, 11-18.

Lampris, C., Stegemann, J.A., Pellizon-Birelli, M., Fowler, G.D., Cheeseman, C.R., 2011. Metal leaching from monolithic stabilised/solidified air pollution control residues. J. Hazard. Mater. 185, 1115-1123.

Lasheras-Zubiate, M., Navarro-Blasco, I., Álvarez, J.I., Fernández, J.M., 2011. Interaction of carboxymethylchitosan and heavy metals in cement media. J. Hazard. Mater. 194, 223231.

Lasheras-Zubiate, M., Navarro-Blasco, I., Fernández, J.M., Álvarez, J.I., 2012. Encapsulation, solid-phases identification and leaching of toxic metals in cement systems modified by natural biodegradable polymers. J. Hazard. Mater. 233-234, 7-17.

Lertwattanaruk, P., Makul, N., Siripattarapravat, C., 2012. Utilization of ground waste seashells in cement mortars for masonry and plastering. J. Environ. Manage. 111, 133-141.

Li, S., Yi, Z., Wang, W., Zhao, F., Liu, B., Hu, J., 2007. Fundamental study on chemical stability of phosphoaluminate cement hardened pastes. Mater. Res. Innov. 11, 78-82.

Liu, J., Nie, X., Zeng, X., Su, Z., 2013. Long-term leaching behavior of phenol in cement/activated-carbon solidified/stabilized hazardous waste. J. Environ. Manage. 115, 265-269. 
Liu, Q., Liu, Y., 2003. Distribution of $\mathrm{Pb}$ (II) species in aqueous solutions. J. Colloid Interf. Sci. 268, 266-269.

Ma, W., Brown P.W., 1994. Hydration of sodium phosphate-modified high alumina cement. J. Mater. Res. 9, 1291-1297.

Malviya, R., Chaudhary R., 2006. Leaching behaviour and immobilization of heavy metals in solidified/stabilizaed products. J. Hazard. Mater. 137, 207-217.

Moon, D.H., Dermatas, D., 2006. An evaluation of lead leachability from stabilized/solidified soils under modified semi-dynamic leaching conditions, Eng. Geol. 85, 67-74.

Naganathan, S., Abdul Razak, H., Nadzriah, S., Hamid, A., 2013. Corrosivity and leaching behavior of controlled low-strength material (CLSM) made using bottom ash and quarry dust. J. Environ. Manage. 128, 637-641.

Navarro-Blasco, I., Duran, A., Sirera, R., Fernández, J.M., Alvarez, J.I., 2013. Solidification/stabilization of toxic metals in calcium aluminate cement matrices. J. Hazard. Mater. 260, 89-103.

Noruzman, A.J., Muhammad, B., Ismail, M., Abdul-Majid, Z., 2012. Characteristics of treated effluents and their potential applications for producing concrete, J. Environ. Manage. 110, 27-32.

Ojovan, M.I., Varlackova, G.A., Golubeva, Z.I., Burlaka, O.N., 2011. Long-term field and laboratory leaching tests of cemented radioactive wastes. J. Hazard. Mater. 187, 296-302.

Pandey, B., Kinrade, S.D., Catalan, L.J.J., 2012. Effects of carbonation on the leachability and compressive strength of cement-solidified and geopolymer-solidified synthetic metal wastes. J. Environ. Manage. 101, 59-67.

Phuong, N.V., Lee, K.H., Chang, D., Moon, S., 2013. Effects of $\mathrm{Zn}^{2+}$ concentration and $\mathrm{pH}$ on the zinc phosphate conversion coatings on AZ31 magnesium alloy. Corros. Sci. 74, 314-322.

Protopopoff, E., Marcus, P., 2005. Potential-pH diagrams for hydroxyl and hydrogen adsorbed on a copper surface. Electrochim. Acta 51, 408-417.

Puigdomenech, I., 2004. Hydra/Medusa Chemical Equilibrium Database and Plotting Software.KTH Royal Institute of Technology.

Sakai, E., Sugiyama, T., Saito, T., Daimon, M., 2010. Mechanical properties and microstructures of calcium aluminate based ultra high strength cement. Cement Concrete Res. 40, 966-970.

Shaheen,S.M., Eissa,F.I., Ghanem,K.M., Gamal El-Din,H.M., Al Anany,F.S., 2013. Heavy metals removal from aqueous solutions and wastewaters by using various byproducts. J. Environ. Manage. 128, 514-521. 
Sugama, T., Carciello N.R., 1991. Strength development in phosphate-bonded calcium aluminate cements. J. Am. Ceram. Soc. 74, 1023-1030.

Sugama, T., Carciello N.R., 1992. Carbonation of hydrothermally treated phosphatebonded calcium aluminate cements. Cement Concrete Res. 22, 783-792.

Sugama, T., Carciello, N.R., 1995. Sodium phosphate-derived calcium phosphate cements. Cement Concrete Res. 25, 91-101.

Sugama, T., Weber, L., Brothers, L.E., 1999. Resistance of sodium polyphosphate-modified fly ash/calcium aluminate blend cements to hot $\mathrm{H}_{2} \mathrm{SO}_{4}$ solution. Cement Concrete Res. 29, 1969-1976.

Sugama,T., 1996. Hot alkali carbonation of sodium metaphosphate modified fly ash/calcium aluminate blend hydrothermal cements. Cement Concrete Res. 26, 1661-1672.

Swift, P., Kinoshita, H., Collier, N.C., 2013a. The Effect of Supplementary Pulverised Fuel Ash on Calcium Aluminate Phosphate Cement for Intermediate-Level Waste Encapsulation, in: Bart, F., Cau di Coumes, C., Frizon, F., Lorente, S. (Eds.), Cement-Based Materials for Nuclear Waste Storage. Spinger Science+Business Media, New York, pp 215-224.

Swift, P., Kinoshita, $H_{\ddot{\prime}}$ Collier, N.C., Utton, C.A., 2013b. Phosphate modified calcium aluminate cement for radioactive waste encapsulation. Adv. Appl. Ceram. 112, 1-8.

Torras, J., Buj, I., Rovira, M., de Pablo, J., 2011. Semi-dynamic leaching tests of nickel containing wastes stabilized/solidified with magnesium potassium phosphate cements. J. Hazard. Mater. 186, 1954-1960.

Torréns-Martín, D., Fernández-Carrasco, L., Martínez-Ramírez, S., 2013. Hydration of calcium aluminates and calcium sulfoaluminate studied by Raman spectroscopy. Cement Concrete Res. 47, 43-50.

\section{U.S. Nuclear Regulatory Commission, 1991. Waste Form Technical Position.}

Ucaroglu, S., Talinli, İ., 2012. Recovery and safer disposal of phosphate coating sludge by solidification/stabilization, J. Environ. Manage. 105, 131-137.

Ukrainczyk, N., Vrbos, N., Šipušić, J., 2012. Influence of metal chloride salts on calcium aluminate cement hydration. Adv. Cem. Res. 24, 249-262.

Wagh, A.S., Jeong, S.Y., Singh, D., Strain, R., No, H., Wescott, J., 1997. Stabilization of contaminated soil and waste water with chemically bonded phosphate ceramics, in: Proceedings of the Waste Management Annual Meeting, Tucson, available at http:www.wmsym.org/wm97proceedings/

Wagh, A.S., Jeong, S.Y., 2003. Chemically Bonded Phosphate Ceramics: I, A Dissolution Model of Formation. J. Am. Ceram. Soc. 86, 1838-1844. 
Wagh, A.S., Strain, R., Jeong, S.Y., Reed, D., Krause, T., Singh, D., 1999. Stabilization of Rocky Flats Pu-contaminated ash within chemically bonded phosphate ceramics. J. Nucl. Mater. 265, 295-307.

Walter, D., Odler, I., 1996. Investigation of $\mathrm{MgO}$ and $\mathrm{CaO} / \mathrm{Al}_{2} \mathrm{O}_{3}$ polyphosphate cements. Adv. Cem. Res. 8, 41-46.

Yan, S., Sagoe-Crentsil, K., 2012. Properties of wastepaper sludge in geopolymer mortars for masonry applications, J. Environ. Manage. 112, 27-32.

Yang,Y., Huang, Q., Yang, Y., Huang, Z., Wang, Q., 2011. Formulation of criteria for pollution control on cement products produced from solid wastes in China. J. Environ. Manage. 92, 1931-1937.

Zhang, J., Liu, J., Li, C., Jin, Y., Nie, Y., Li, J., 2009. Comparison of the fixation effects of heavy metals by cement rotary kiln co-processing and cement based solidification/stabilization. J. Hazard. Mater. 165, 1179-1185.

Zhen, G., Lu, X., Zhao, Y., Niu, J., Chai, X., Su, L., Li, Y.-Y., Liu, Y., Du, J., Hojo, T., $\mathrm{Hu}, \mathrm{Y} ., 2$ 2013. Characterization of controlled low-strength material obtained from dewatered sludge and refuse incineration bottom ash: Mechanical and microstructural perspectives. J. Environ. Manage. 129, 183-189. 
Table 1. Cumulative leaching results.

\begin{tabular}{|c|c|c|c|}
\hline $\begin{array}{l}\text { Parameters in studied } \\
\text { samples }^{\mathrm{a}}\end{array}$ & $\begin{array}{c}\text { Curing } \\
\text { condition } 1\end{array}$ & $\begin{array}{c}\text { Curing } \\
\text { condition } 2\end{array}$ & Emission limit ${ }^{c}$ \\
\hline \multicolumn{4}{|l|}{ Control SHMP-CAC mortar } \\
\hline $\mathrm{pH}$ & $9.73 \pm 0.06$ & $9.25 \pm 0.07$ & - \\
\hline Conductivity & $709 \pm 39$ & $239 \pm 25$ & - \\
\hline $\mathrm{Pb}$ cumulative leaching & 0.5 & 0.31 & 400 \\
\hline Zn cumulative leaching & 1.31 & 0.96 & 800 \\
\hline Cu cumulative leaching & $<0.2^{\mathrm{b}}$ & $<0.2^{\mathrm{b}}$ & 98 \\
\hline \multicolumn{4}{|l|}{ Pb-doped SHMP-CAC mortar } \\
\hline $\mathrm{pH}$ & $9.81 \pm 0.14$ & $9.22 \pm 0.13$ & - \\
\hline Conductivity & $676 \pm 66$ & $465 \pm 67$ & - \\
\hline $\mathrm{Pb}$ cumulative leaching & 5.24 & 2.13 & 400 \\
\hline$\% \mathrm{~Pb}$ retained & 99.991 & 99.996 & \\
\hline \multicolumn{4}{|l|}{ Zn-doped SHMP-CAC mortar } \\
\hline $\mathrm{pH}$ & $9.62 \pm 0.04$ & $9.56 \pm 0.11$ & - \\
\hline Conductivity & $624 \pm 18$ & $434 \pm 33$ & - \\
\hline Zn cumulative leaching & 5.03 & 34.36 & 800 \\
\hline$\% \mathrm{Zn}$ retained & 99.991 & 99.938 & \\
\hline \multicolumn{4}{|l|}{ Cu-doped SHMP-CAC mortar } \\
\hline $\mathrm{pH}$ & $10.37 \pm 0.03$ & $10.23 \pm 0.50$ & - \\
\hline Conductivity & $877 \pm 154$ & $852 \pm 136$ & - \\
\hline $\mathrm{Cu}$ cumulative leaching & 5.74 & 0.83 & 98 \\
\hline$\% \mathrm{Cu}$ retained & 99.990 & 99.999 & \\
\hline \multicolumn{4}{|c|}{$\begin{array}{l}{ }^{\text {a }} \text { Values at } 64^{\text {th }} \text { day. Conductivity and metal cumulative leaching expressed in } \mu \mathrm{Scm}^{-1} \text { and } \mathrm{mg} \cdot \mathrm{m}^{-2} \text {, } \\
\text { respectively. }\end{array}$} \\
\hline \multicolumn{4}{|c|}{$\begin{array}{l}{ }^{b} \text { Found concentration level was below limit of detection. Calculated cumulative leaching value has been } \\
\text { obtained from this limit. }\end{array}$} \\
\hline
\end{tabular}


Table 2. Slopes ( \pm standard deviation) of the log-log plots of derived cumulative leaching of metal-doped samples vs. time.

\begin{tabular}{|c|c|c|c|c|c|c|}
\hline \multirow{2}{*}{ Step } & \multicolumn{2}{|c|}{ Zn } & \multicolumn{2}{|c|}{$\mathrm{Cu}$} & \multicolumn{2}{|c|}{$\mathbf{P b}$} \\
\hline & Curing 1 & Curing 2 & Curing 1 & Curing 2 & Curing 1 & Curing 2 \\
\hline $\begin{array}{c}\text { Increment 2- } \\
7 \\
\text { (1-36 days) }\end{array}$ & $0.234 \pm 0.016$ & $0.061 \pm 0.012$ & $0.045 \pm 0.012$ & $0.171 \pm 0.039$ & $0.546 \pm 0.068$ & $0.928 \pm 0.258$ \\
\hline $\begin{array}{c}\text { Increment 1- } \\
4 \\
\text { (0.25-4 days) }\end{array}$ & $0.959 \pm 0.265$ & $0.766 \pm 0.245$ & $0.757 \pm 0.252$ & $0.382 \pm 0.0 .173$ & $1.064 \pm 0.087$ & $1.078 \pm 0.191$ \\
\hline $\begin{array}{c}\text { Increment 2- } \\
5 \\
\text { (1-9 days) }\end{array}$ & $0.220 \pm 0.027$ & $0.090 \pm 0.017$ & $0.075 \pm 0.016$ & $0.0 .252 \pm 0.072$ & $0.607 \pm 0.168$ & $0.766 \pm 0.574$ \\
\hline $\begin{array}{l}\text { Increment } 3- \\
6 \\
\text { (2.25-16 days) }\end{array}$ & $0.235 \pm 0.039$ & $0.054 \pm 0.008$ & $0.051 \pm 0.023$ & $0.102 \pm 0.062$ & $0.385 \pm 0.064$ & $0.889 \pm 0.101$ \\
\hline $\begin{array}{c}\text { Increment 4- } \\
7 \\
\text { (4-36 days) }\end{array}$ & $0.231 \pm 0.037$ & $0.029 \pm 0.006$ & $0.008 \pm 0.004$ & $0.072 \pm 0.039$ & $0.449 \pm 0.075$ & $0.934 \pm 0.100$ \\
\hline $\begin{array}{c}\text { Increment 5- } \\
8 \\
\text { (9-64 days) }\end{array}$ & $0.289 \pm 0.048$ & $0.035 \pm 0.010$ & n.i. $^{a}$ & $0.104 \pm 0.0 .030$ & $0.828 \pm 0.152$ & $0.839 \pm 0.165$ \\
\hline
\end{tabular}




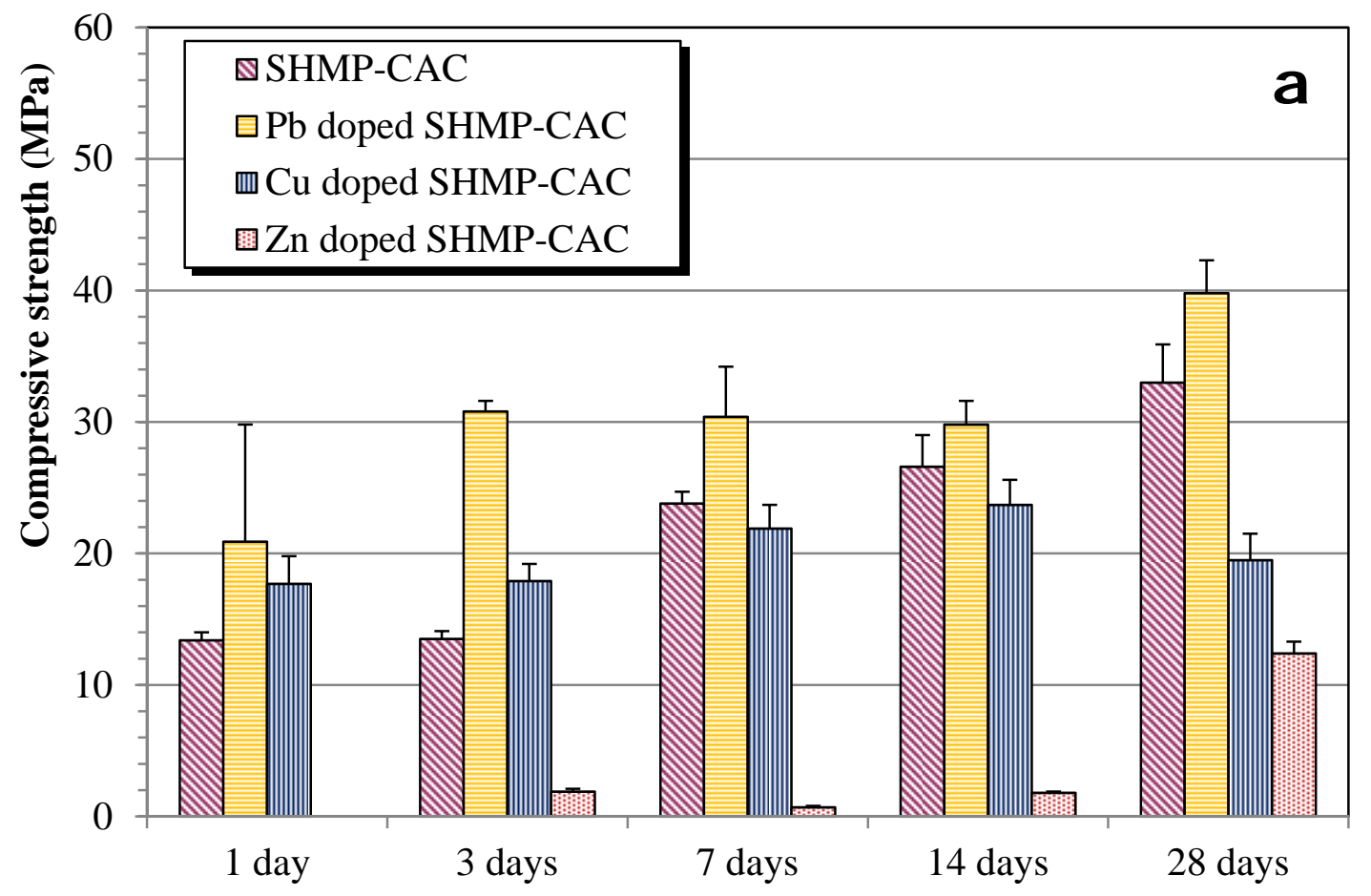

Curing time

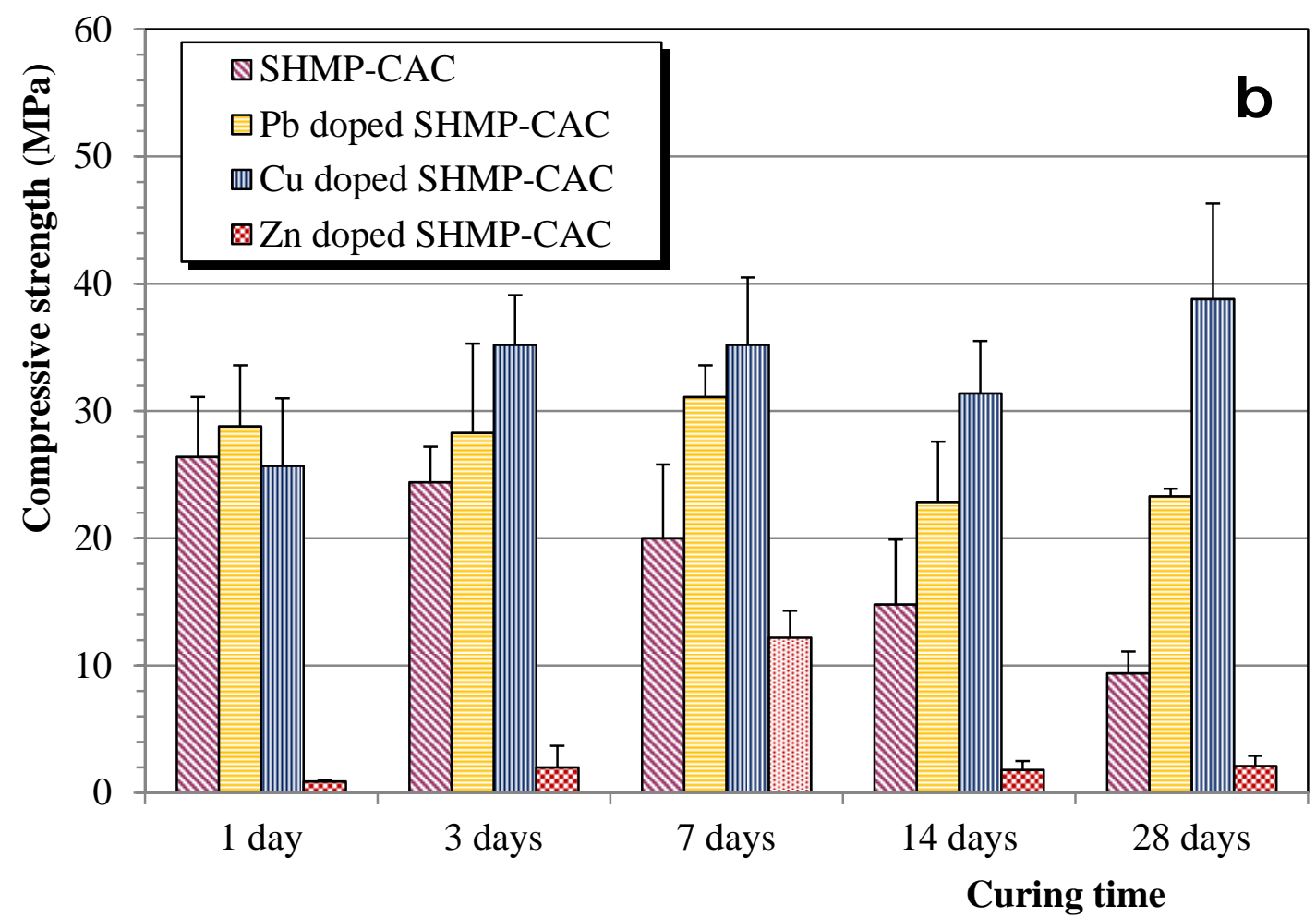

Figure 1. Compressive strengths (MPa) for SHMP-calcium aluminate cement mortars vs. curing time under $\mathbf{a})$ curing condition 1 and $\mathbf{b}$ ) curing condition 2 . 


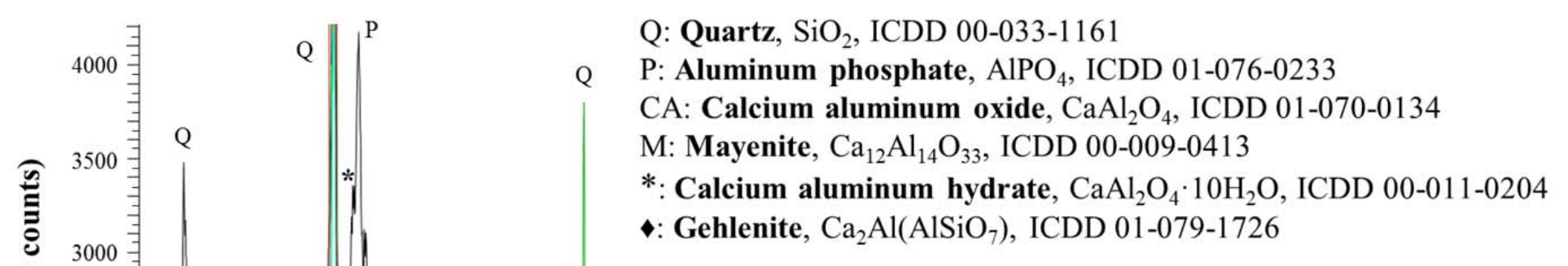

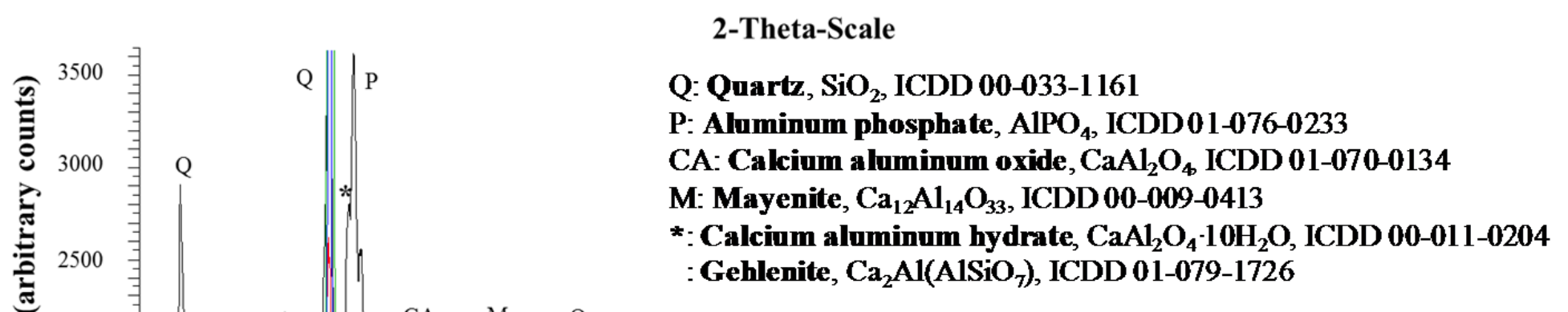

2-Theta-Scale 


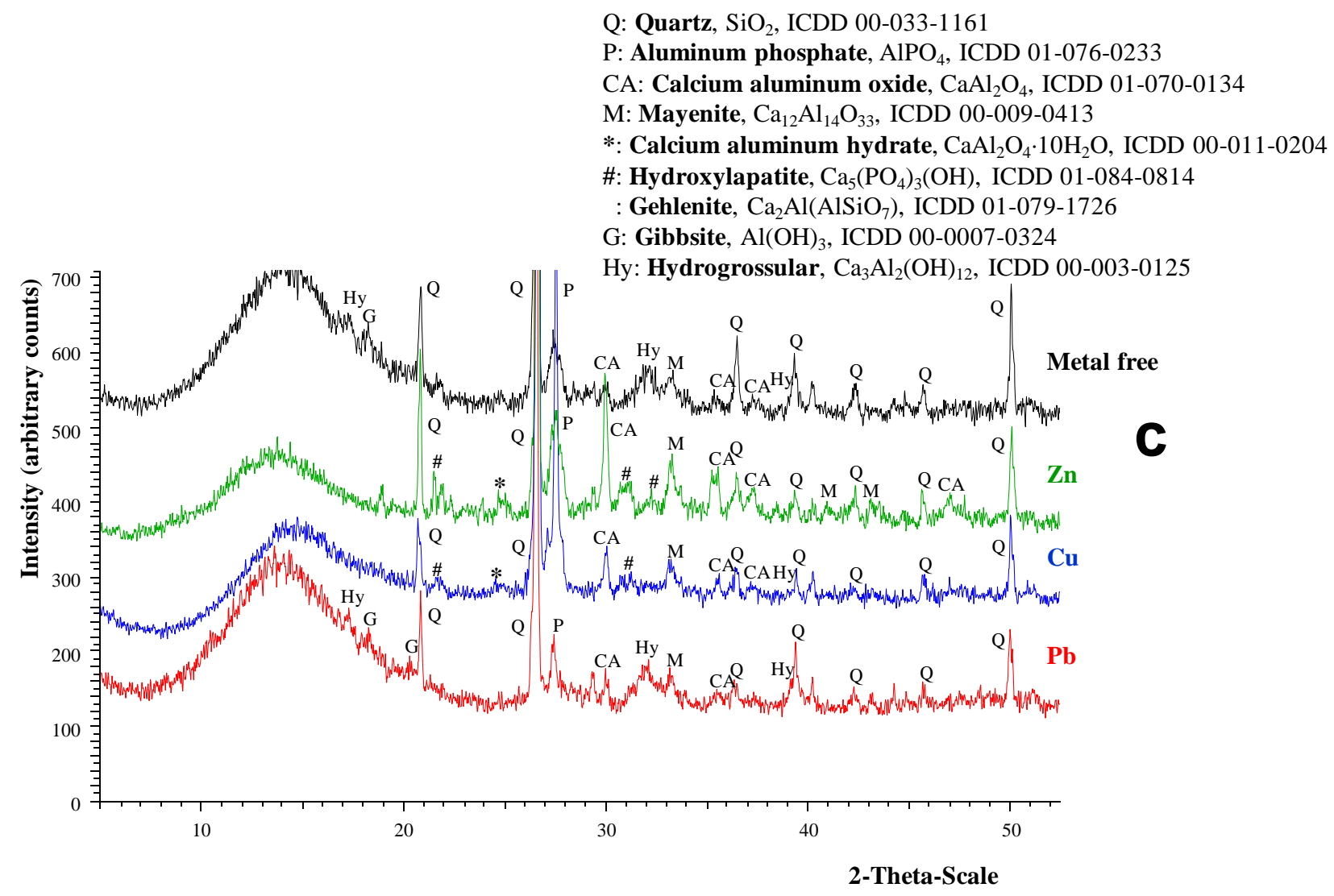

Figure 2. a) XRD of metal-free samples at different curing ages; b) XRD of $\mathrm{Pb}-$, Cuand $\mathrm{Zn}$-doped and metal-free samples after 28 curing days under curing condition 1 and $\mathbf{c}$ ) under curing condition 2. 

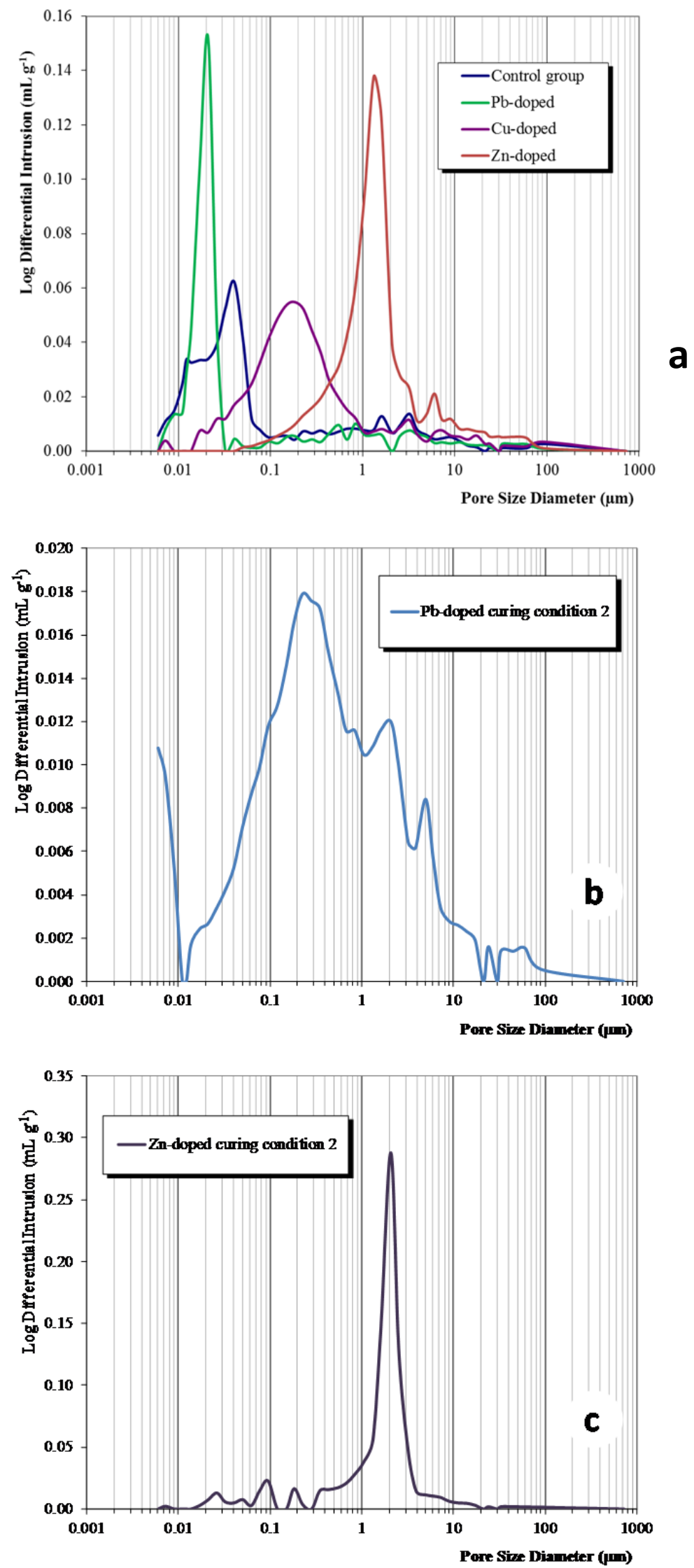

Figure 3. a) PSD of metal-free (control group), $\mathrm{Pb}$-, Cu- and $\mathrm{Zn}$-doped SHMP-CAC aged 28 days under curing condition 1. PSD of $\mathbf{b}) \mathrm{Pb}$ - and $\mathbf{c}$ ) Zn-doped SHMP-CAC mortars after 28 days under curing condition 2. 


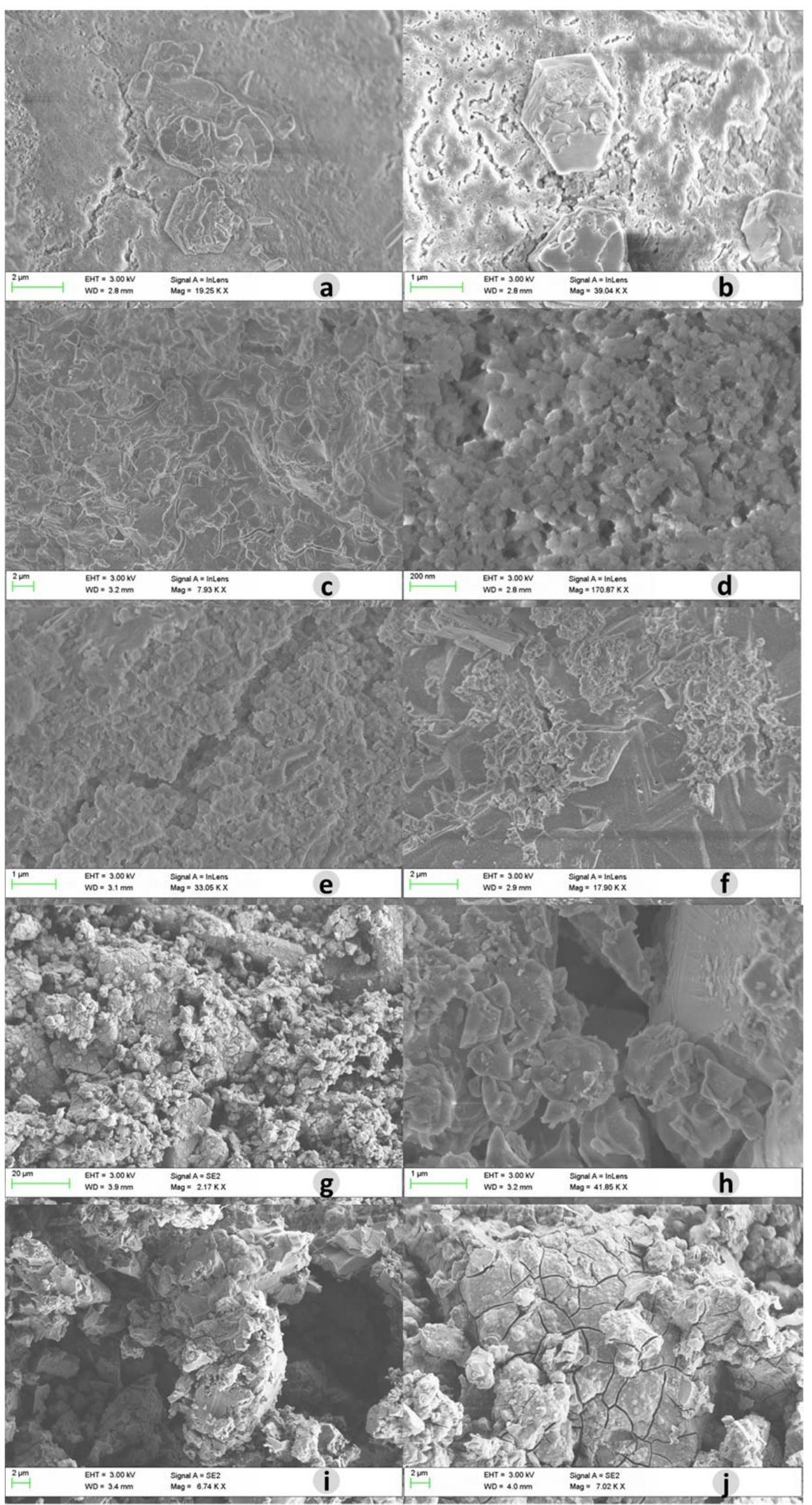


Figure 4. Micrographs after 28 days of curing condition 1 of: metal-free phosphatemodified CAC showing: a) glassy structured with some quasi-prismatic crystals and b) area with several microcracks on the surface. $\mathrm{Pb}$-doped phosphate-modified CAC with: c) amorphous structure with a high degree of compactness and d) detail at higher magnification of the amorphous structure, showing a continuous binding matrix with small size of pores. Cu-doped SHMP-CAC depicting in: e) severe microcracks in a rather heterogeneous matrix and f) interconnected areas of different textural aspects, with single crystals and clusters of crystals spread over the surface of the sample. Finally, Zn-doped SHMP-CAC samples showing in: g) deposits of anhydrous calcium aluminate compounds; $h$ ) and i) details of the sample depicting large pores and a poorly developed binding matrix; and j) abundance of microcracks on a glassy matrix.

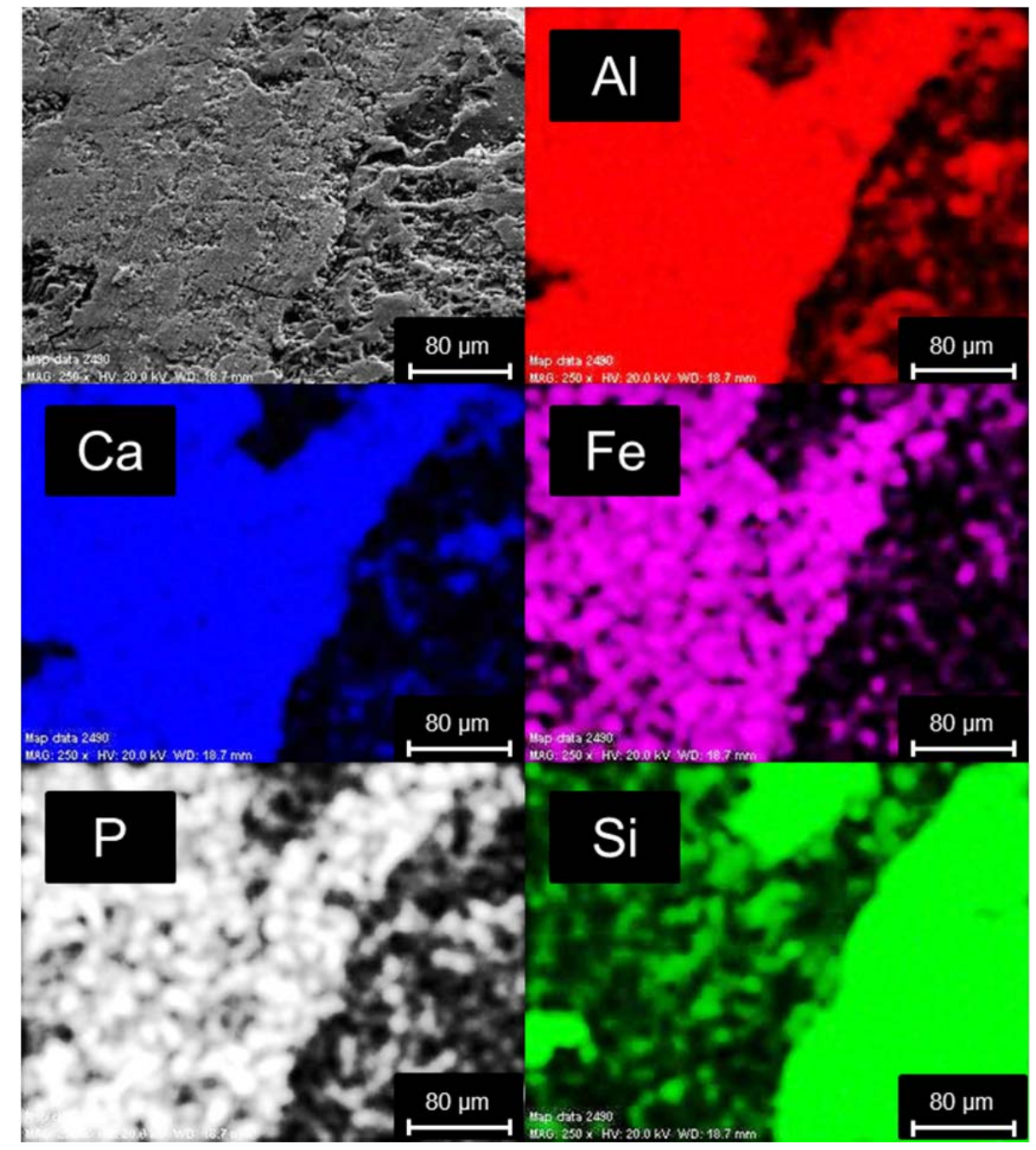

Figure 5. Elemental mapping of a metal-free SHMP-CAC matrix. 


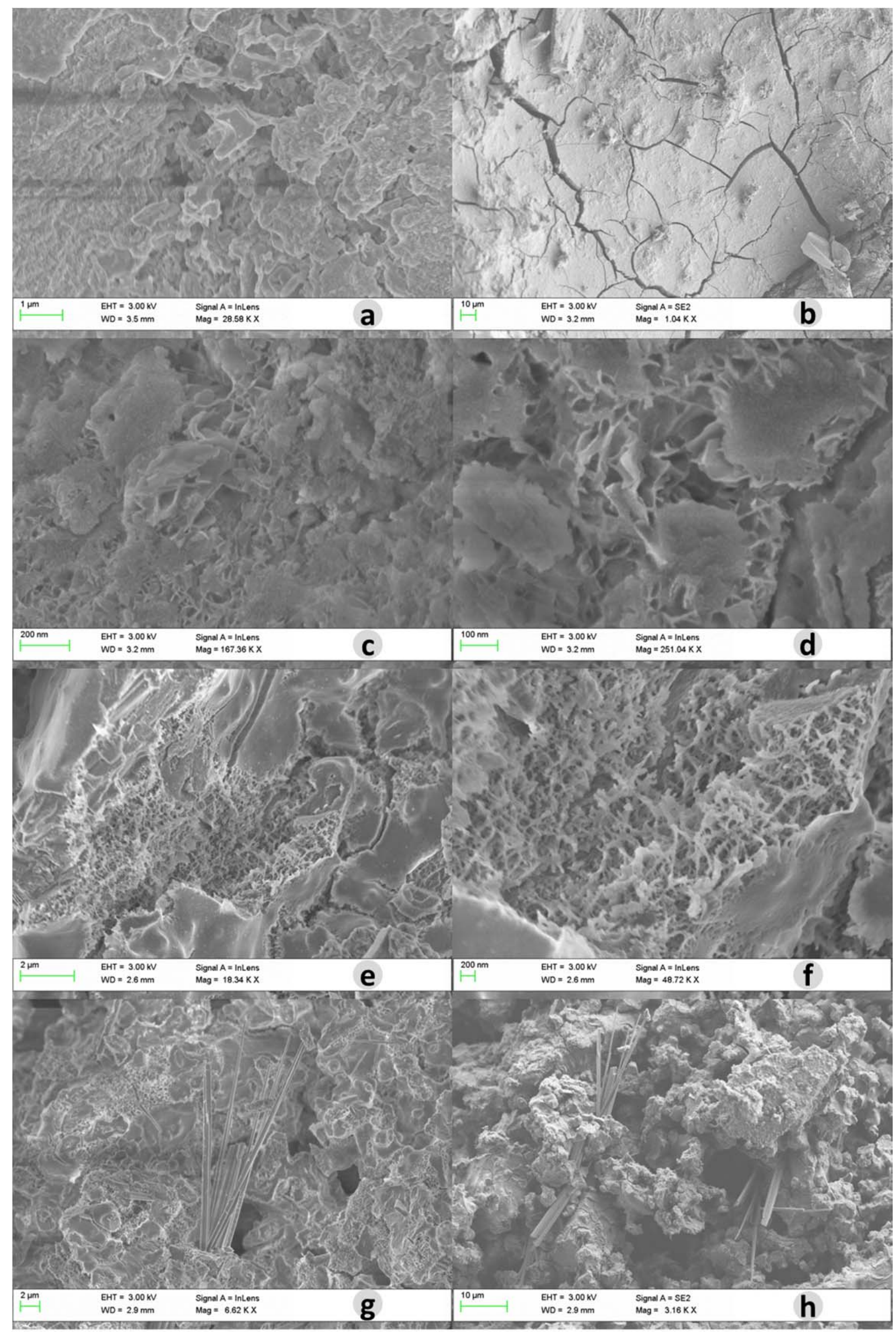


Figure 6. SEM images of samples after 28 days of curing under condition 2. For $\mathrm{Pb}$-doped phosphate-modified CAC: a) porous, poorly interconnected binding matrix; and b) severe microcracks. For Cu-doped SHMP-CAC specimens: c) interlinked flaky, plate-like crystals of metastable calcium aluminate hydrates; and d) a detailed micrograph at higher magnification. Finally, for Zn-doped phosphatemodified CAC mortars : e) heterogeneous matrix, with microcracks and sponge-like areas; f) a detail examination of this last area; g) growth of needle-shaped crystals; and h) general overview of the matrix, showing large pores, poor binder development and acicular compounds.

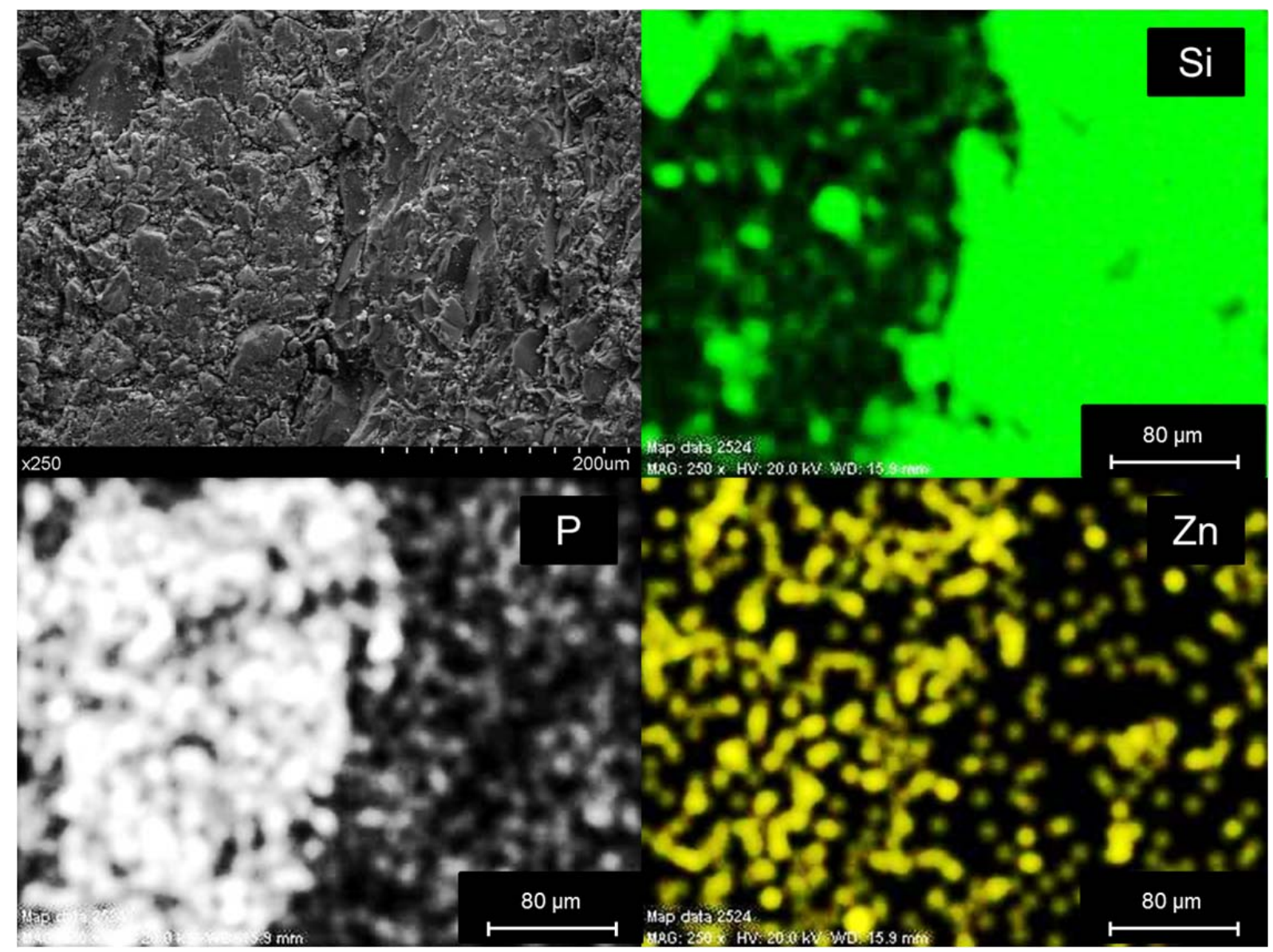

Figure 7. Elemental mapping of a Zn-doped sample (28 days, curing 2), showing, in the brightest spots, the Zn preferentially attached to $\mathrm{P}$ (left part of the micrographs). 


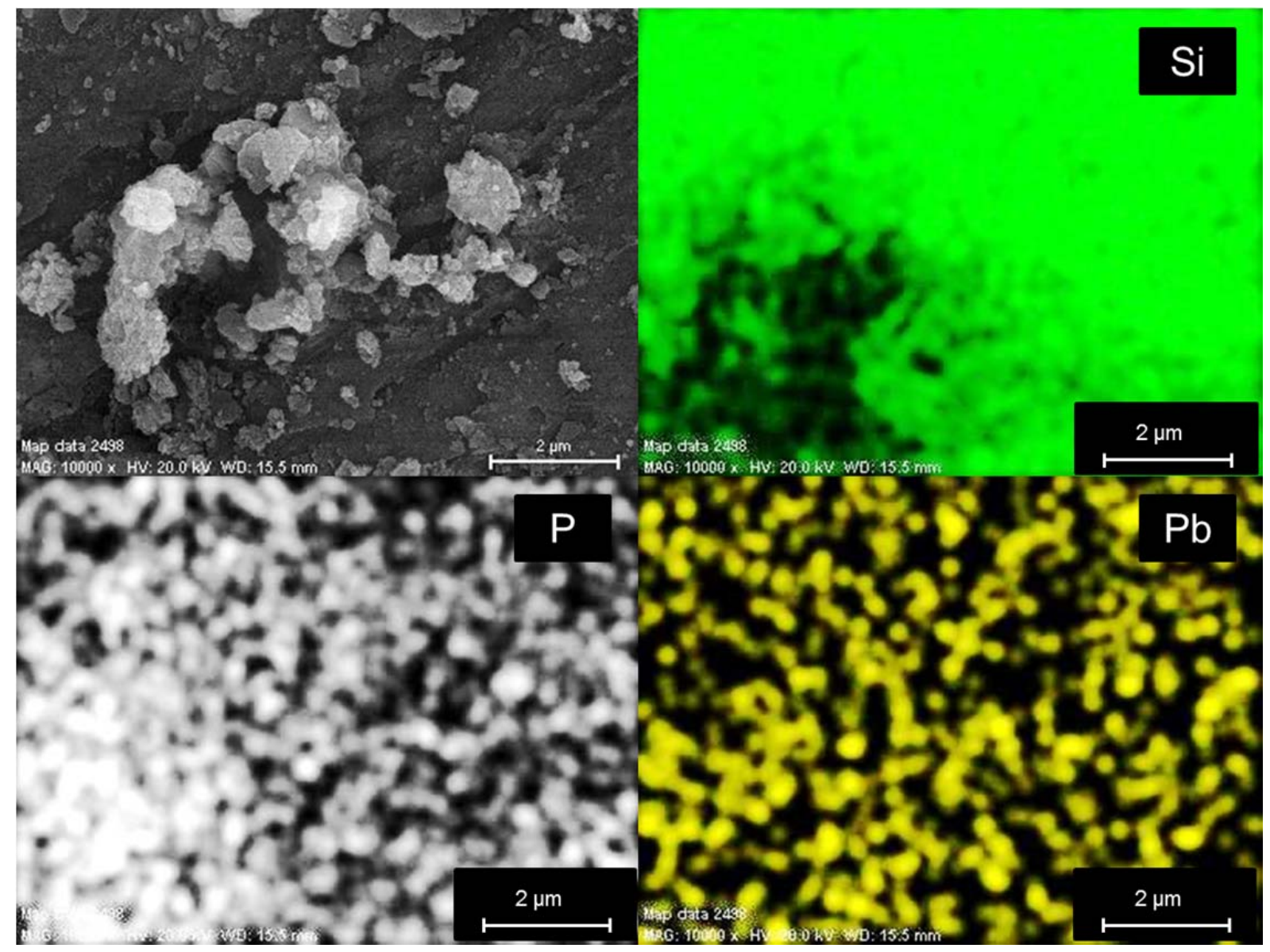

Figure 8. Elemental mapping of a Pb-doped sample (28 days, curing 2), showing,that $\mathrm{Pb}$, bottom-right micrograph, is spread homogeneously all over the sample, showing no preferential attachment to $P$ (which is accumulated in the bottom-left side of the image, as seen by the brightest area). 


\title{
Supplementary Material
}

Treatment of toxic metal aqueous solutions: encapsulation in a phosphatecalcium aluminate matrix

\author{
J.M. Fernández ${ }^{\text {a }}$ I. Navarro-Blasco ${ }^{a}$,A. Duran ${ }^{a}$, R. Sirera ${ }^{a}$, J.I. Alvarez ${ }^{a^{*}}$
}

${ }^{a}$ Inorganic Materials \& Environment (MIMED), Department of Chemistry and Soil Sciences, School of Sciences, University of Navarra. Irunlarrea, 1. 31008 Pamplona, Spain

\section{Section S1. Calculations for the leaching parameters determination}

The measured cumulative leaching for each component was calculated using equation (Eq. S1) and derived cumulative leaching according to equation (Eq. S2), as described in the norm (EA NEN 7375, 2004):

$$
\begin{aligned}
& \varepsilon_{n}^{*}=\sum_{1=n}^{n} E_{i}^{*} \quad \text { for } \mathrm{n}=1 \text { to } \mathrm{N} \\
& \left.\varepsilon_{n}=\frac{\left(E_{i}^{*} \times \sqrt{t_{i}}\right)}{\left(\sqrt{t_{i}}-\sqrt{t_{i-1}}\right)} \text { for } \mathrm{n}=1 \text { to } \mathrm{N} \text { (where } \mathrm{i}=\mathrm{n}\right)
\end{aligned}
$$

where $\varepsilon_{n}{ }^{*}$ is the measured cumulative leaching of a component for a period $N$ comprising fraction $i=1$ to $n$ in $\mathrm{mg} \mathrm{m}^{-2}, E_{i}^{*}$ is the measured leaching of the component in fraction i in $\mathrm{mg} \mathrm{m}^{-2}, \mathrm{~N}$ is the number of replenishing periods, $\varepsilon_{\mathrm{n}}$ is the derived cumulative leaching of a component for a period $\mathrm{N}$ comprising fraction $\mathrm{i}=1$ to $\mathrm{n}$ in $\mathrm{mg} \mathrm{m}^{-2}, \mathrm{t}_{\mathrm{i}}$ is the replenishing time of fraction $\mathrm{i}$ in $\mathrm{s}$ and $\mathrm{t}_{\mathrm{i}-1}$ is the replenishing time of fraction $\mathrm{i}-1$ in $\mathrm{s}$.

The slopes of the linear regression analysis (log-log plots of cumulative leaching vs. time) were calculates from a set of eight data points, in different increments of time, as detailed in the EA NEN 7375: 2004 norm. Gradients below 0.35 indicated surface wash-off (in the case of increment from 0.25 to 4 days) or depletions (for all the rest of time increments); when the gradient was between 0.35 and 0.65 the mechanism was diffusion (for all the studied time intervals), whereas values higher 
than 0.65 indicated delayed diffusion (interval from 0.25 to 4 days) or dissolution (for all the rest of time increments).

The negative logarithm of the effective diffusivity $\left(\mathrm{pD}_{\mathrm{e}}\right)$ (leachability index) was calculated as an indicator of the leaching rate for each metal, according to:

$\mathrm{D}_{\mathrm{e}}=\left(\frac{\varepsilon_{64}}{2653 \cdot \rho \cdot \mathrm{U}_{\text {avail }}}\right)^{2} \cdot \mathrm{f}$

Where $D_{e}$ is the effective diffusion coefficient $\left(\mathrm{m}^{2} \mathrm{~s}^{-1}\right), \varepsilon_{64}$ is the derived cumulative leaching after 64 days $\left(\mathrm{mg} \mathrm{m}^{-1}\right), \rho$ is the density of the specimen $\left(\mathrm{kg} \mathrm{m}^{-3}\right), U_{\text {avail }}$ is the leachable available quantity of the component in mg per kg of dry matter and $f$ corresponds to a unitary value $\left(\mathrm{s}^{-1}\right)$.

Table S1. Langmuir and Freundlich adsorption parameters.

\section{Langmuir model}

\section{Freundlich model}

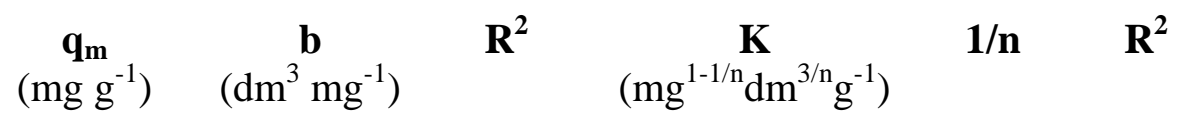

\section{$\mathbf{P b}(\mathbf{I I})$}

$\begin{array}{lllllll}\text { Nitrate } & 19.46^{\mathrm{a}} & 0.001 & 0.448 & 3.467 & 0.164 & 0.562 \\ \text { Chloride } & 35.07^{\mathrm{a}} & 0.001 & 0.422 & 2.130 & 0.306 & 0.755\end{array}$

$\mathrm{Cu}(\mathrm{II})$

$\begin{array}{llllcll}\text { Nitrate } & 66.03 & 0.005 & 0.998 & 0.8563 & 0.553 & 0.803 \\ \text { Chloride } & 90.79 & 0.001 & 0.909 & 7.646 & 0.260 & 0.989\end{array}$

Zn(II)

\begin{tabular}{lllllll} 
Nitrate & $52.48^{\mathrm{a}}$ & 0.0004 & 0.315 & 0.1052 & 0.706 & 0.926 \\
Chloride & 55.98 & 0.0007 & 0.915 & 0.2320 & 0.643 & 0.925 \\
\hline
\end{tabular}

$\mathrm{q}_{\mathrm{m}}$ : maximum sorption capacity

b: the Langmuir constant

$\mathrm{K}, 1 / \mathrm{n}$ : the Freundlich constants

$\mathrm{R}^{2}$ : correlation coefficient of the linear regression

${ }^{\mathrm{a}}$ Scarcely statistically significant data arising from poor adjustment to the sorption model 
Table S2. Maximum sorption capacities (mg divalent metal/g sorbent material) reported in the literature.

\begin{tabular}{lcccccc}
\hline $\begin{array}{c}\text { Zeolite- } \\
\text { OPC } \\
\text { (Ok et al. } \\
\text { 2007) }\end{array}$ & $\begin{array}{c}\text { Crushed } \\
\text { concrete } \\
\text { fines } \\
\text { (Coleman et } \\
\text { al. 2005) }\end{array}$ & $\begin{array}{c}\text { Unmodified } \\
\text { CAC } \\
\text { (Navarro- } \\
\text { Blasco et al. } \\
\text { 2013) }\end{array}$ & $\begin{array}{c}\text { Olive stone } \\
\text { waste } \\
\text { (Fiol et al. } \\
\text { 2006) }\end{array}$ & $\begin{array}{c}\text { Tourmaline } \\
\text { (Liu, Wang et } \\
\text { al. 2013) }\end{array}$ & $\begin{array}{c}\text { Natural } \\
\text { zeolite } \\
\text { (Yousef et al. } \\
\text { 2009) }\end{array}$ \\
\hline $\mathbf{P b ( I I ) ~}$ & 27.03 & 37 & 28.35 & 9.25 & - & - \\
$\mathbf{C u ( I I ) ~}$ & 23.25 & 35 & 59.04 & 2 & - & 52.7 \\
$\mathbf{Z n ( I I ) ~}$ & 12.85 & 33 & 26.59 & - & 28.8 & - \\
\hline
\end{tabular}

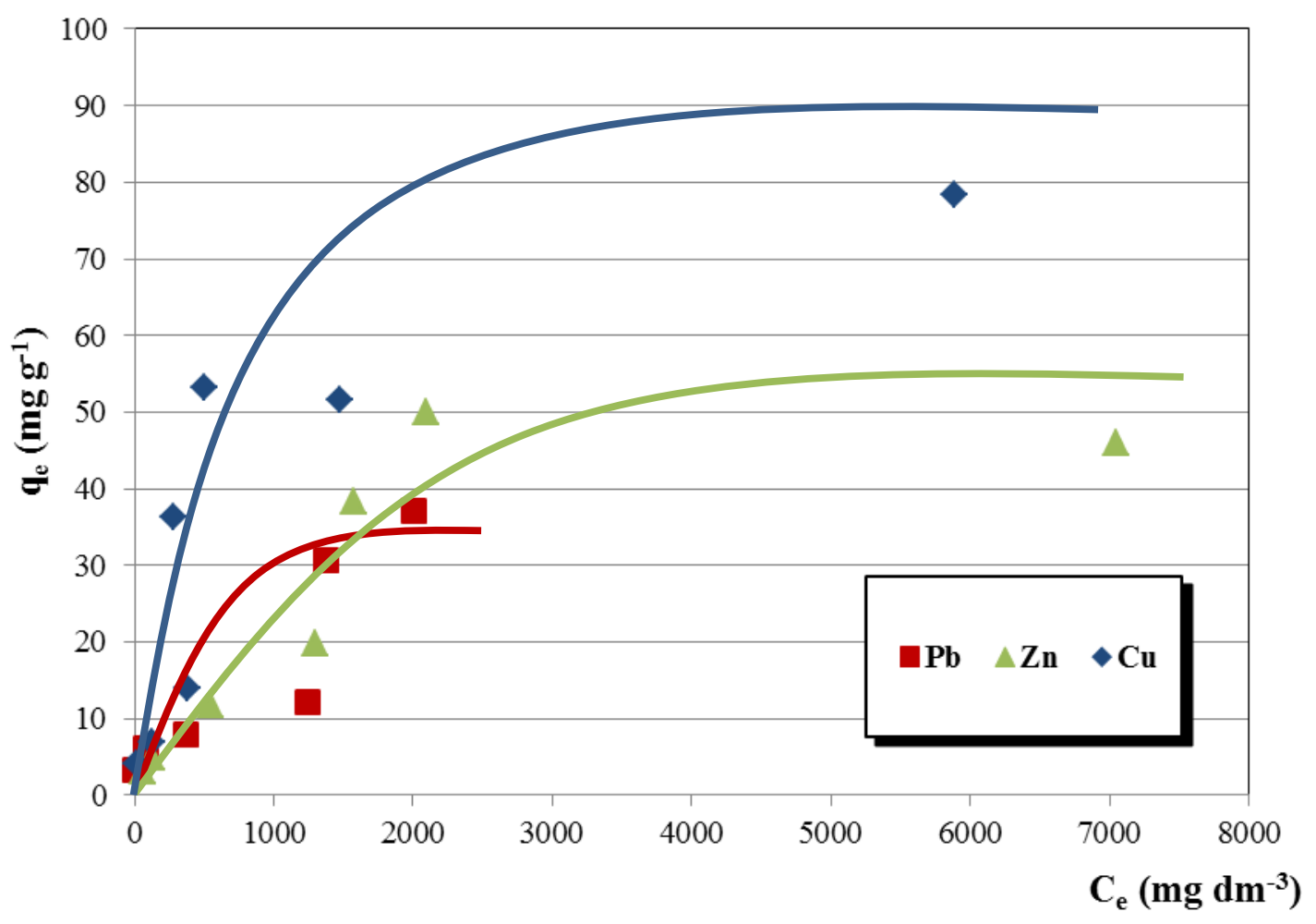

Figure S1. Adsorption isotherms: metal chlorides. 


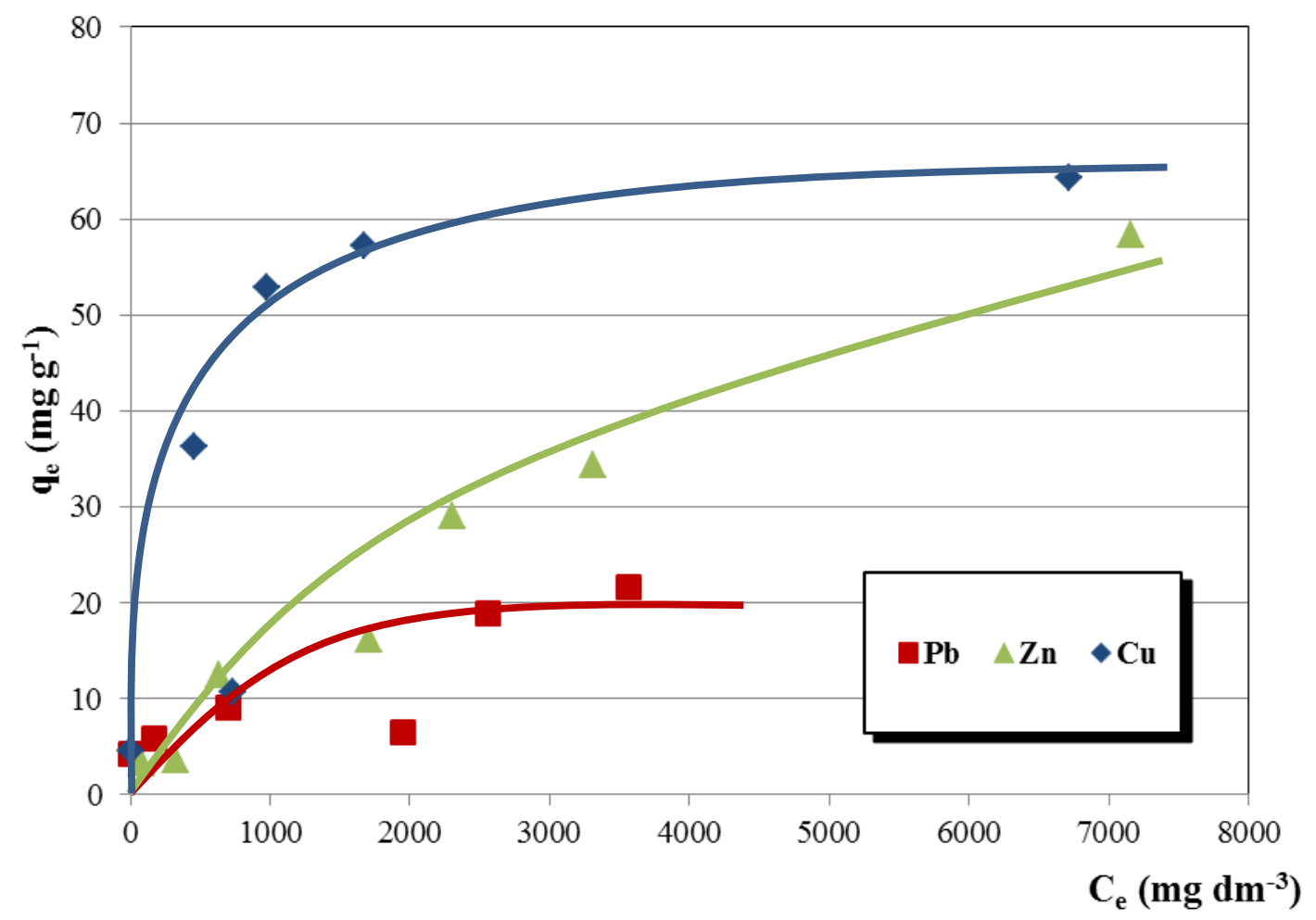

Figure S2. Adsorption isotherms: metal nitrates.

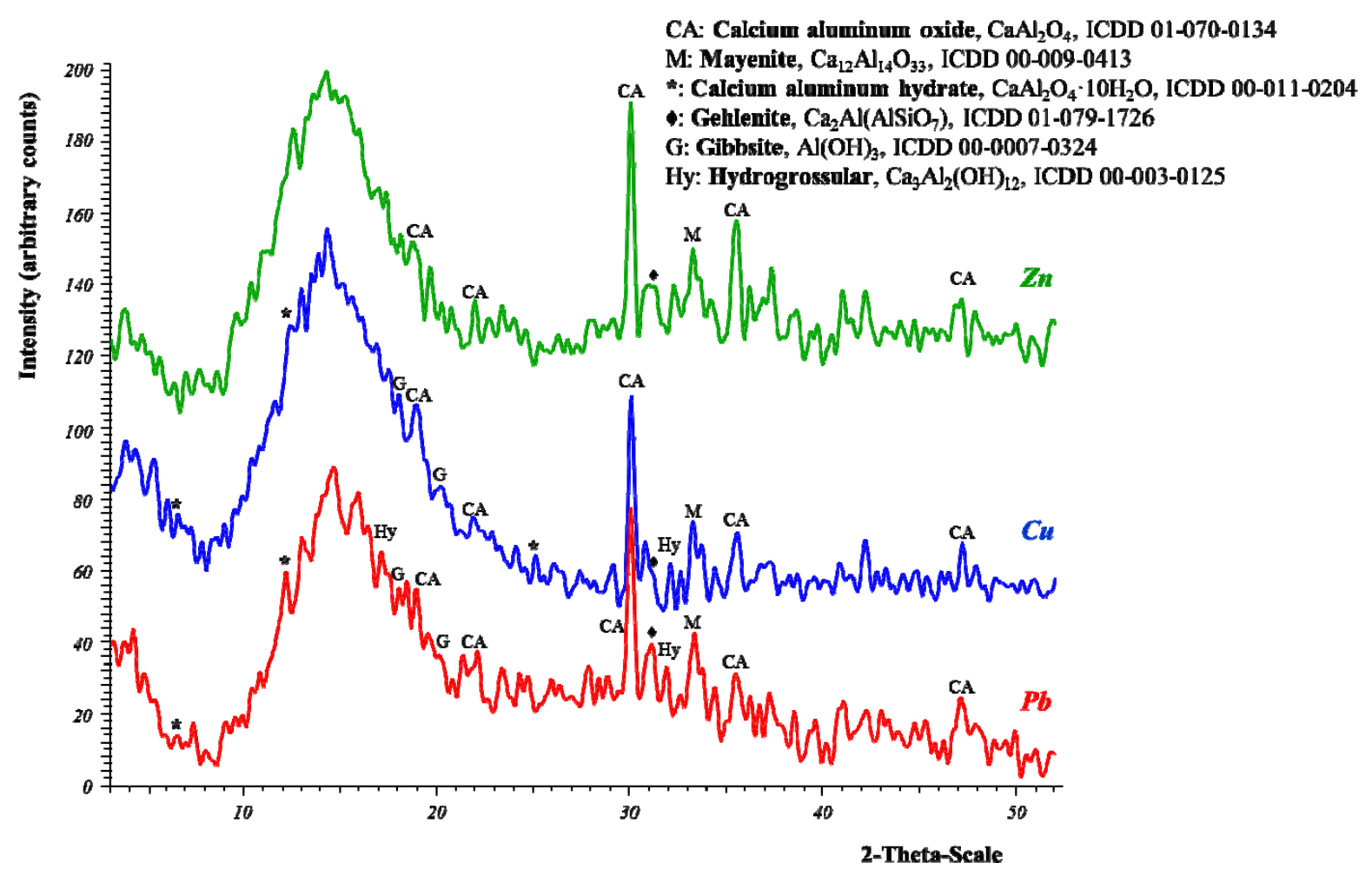

Figure S3. XRD of solid fraction of samples after sorption studies $(10 \% \mathrm{w} / \mathrm{w}$ metal/binder fraction). 


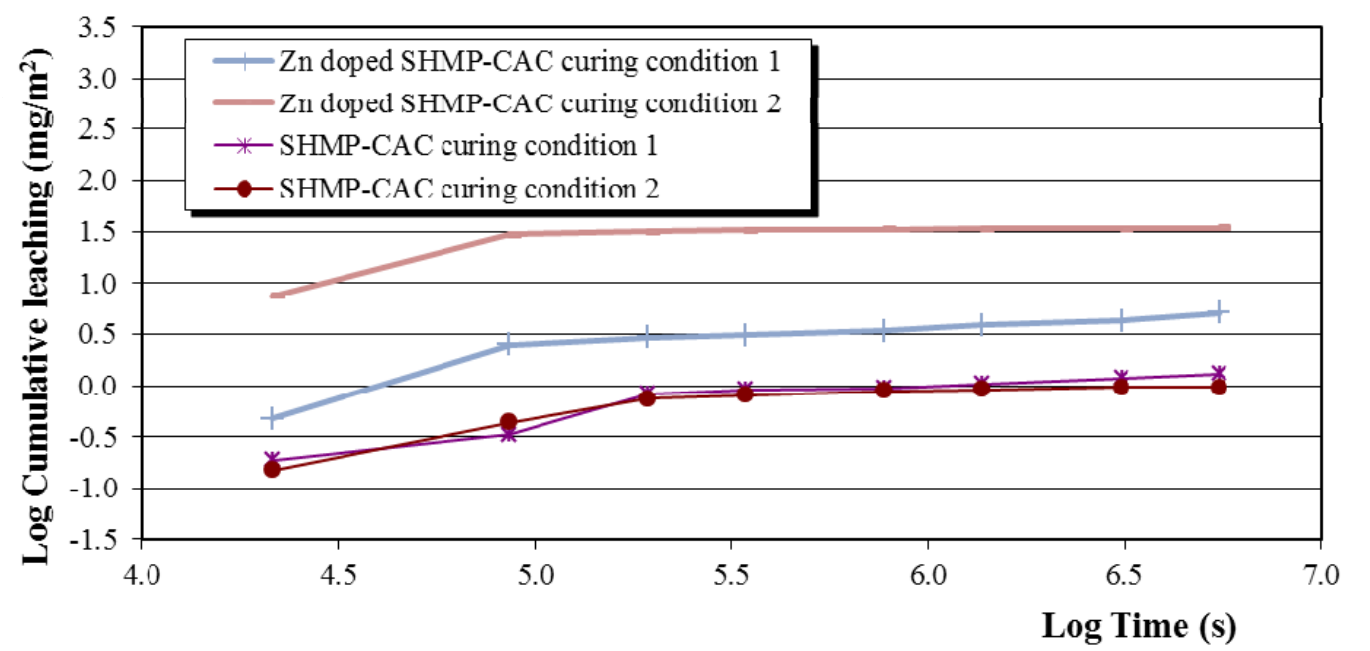

a

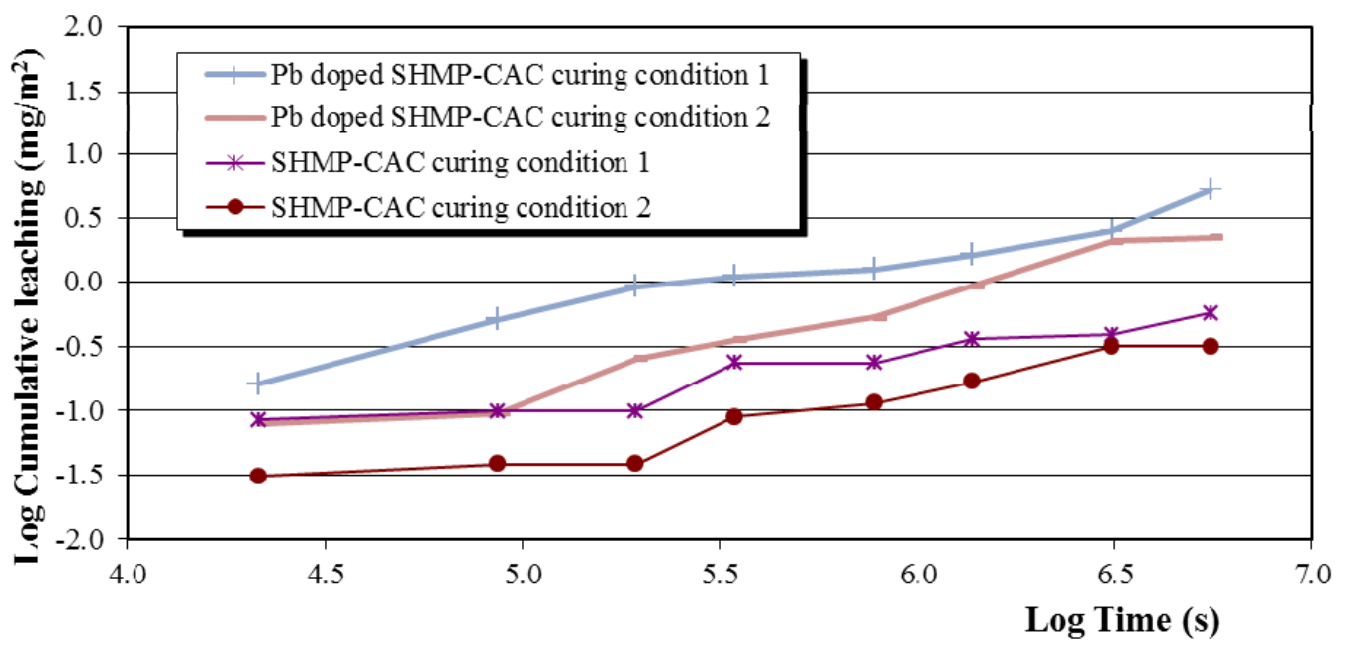

b

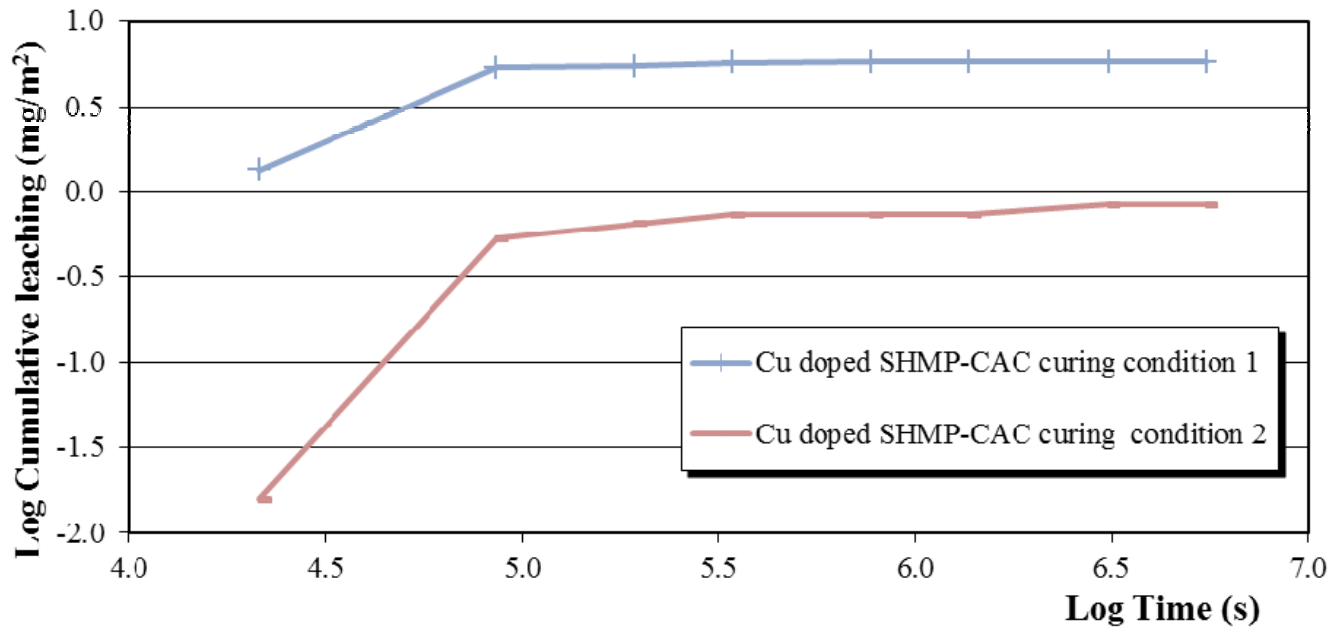

Figure S4. Log of cumulative leaching vs. log of time for (a) $\mathrm{Zn}$, (b) $\mathrm{Pb}$ and (c) $\mathrm{Cu}$ over 64 days. For $\mathrm{Cu}$, plain mortars values are not shown because the contents were below the detection limits. 

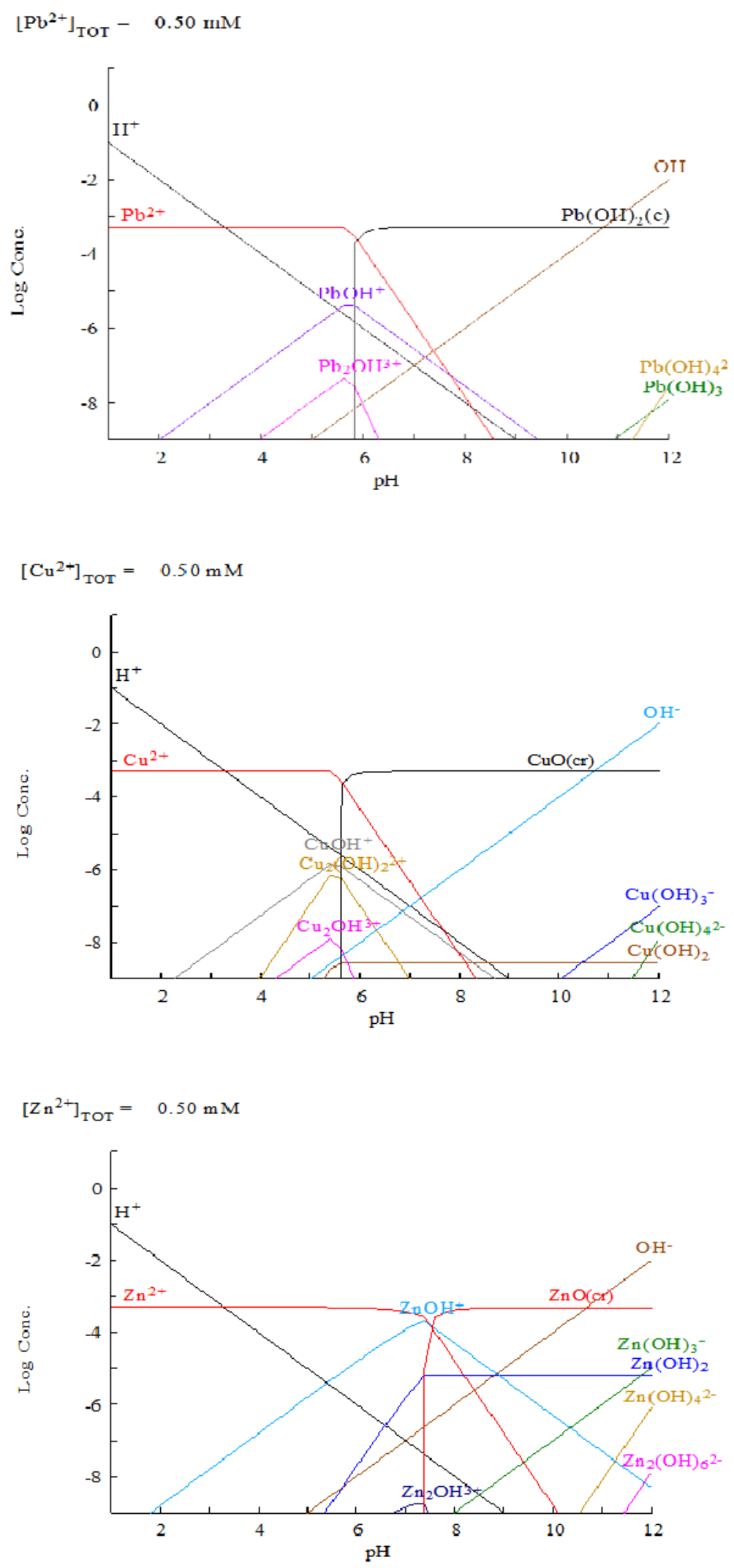

Figure S5. Chemical equilibria diagrams for the assayed metals in aqueous media vs. pH values. 


\section{References of the Supplementary Material}

Coleman, N.J., Lee, W.E., Slipper, I.J., 2005. Interactions of aqueous $\mathrm{Cu}^{2+}, \mathrm{Zn}^{2+}$ and $\mathrm{Pb}^{2+}$ ions with crushed concrete fines. J. Hazard. Mater. 121, 203-213.

Fiol, N., Villaescusa, I., Martínez, M., Miralles, N., Poch, J., Serarols, J., 2006. Sorption of $\mathrm{Pb}(\mathrm{II}), \mathrm{Ni}(\mathrm{II}), \mathrm{Cu}(\mathrm{II})$ and $\mathrm{Cd}(\mathrm{II})$ from aqueous solution by olive stone waste. Sep. Purif. Technol. 50, 132-140.

Liu, H., Wang, C., Liu, J., Wang, B.L., Sun, H., 2013. Competitive adsorption of Cd(II), $\mathrm{Zn}$ (II) and $\mathrm{Ni}$ (II) from their binary and ternary acidic systems using tourmaline. J. Environ. Manage. 128, 727-734.

Navarro-Blasco, I., Duran, A., Sirera, R., Fernández, J.M., Alvarez, J.I., 2013. Solidification/stabilization of toxic metals in calcium aluminate cement matrices. J. Hazard. Mater. 260, 89-103.

Ok, Y.S., Yang, J.E., Zhang, Y.S., Kim, S.J., Chung, D.Y., 2007. Heavy metal adsorption by a formulated zeolite-Portland cement mixture. J. Hazard. Mater. 147, 91-96.

Yousef, R.H., El-Eswed, B., Alshaaer, M., Khalili, F., Khoury, H., 2009. The influence of using Jordanian natural zeolite on the adsorption, physical, and mechanical properties of geopolymers products. J. Hazard. Mater. 165, 379-387. 